\title{
The Differential Contribution of the Innate Immune System to a Good Pathological Response in the Breast and Axillary Lymph Nodes Induced by Neoadjuvant Chemotherapy in Women with Large and Locally Advanced Breast Cancers
}

\author{
Viriya Kaewkangsadan, ${ }^{1}$ Chandan Verma, ${ }^{1}$ Jennifer M. Eremin, ${ }^{2}$ Gerard Cowley, ${ }^{3}$ \\ Mohammad Ilyas, ${ }^{4}$ Sukchai Satthaporn, ${ }^{5}$ and Oleg Eremin ${ }^{1,2}$ \\ ${ }^{1}$ Division of Gastrointestinal Surgery, Nottingham Digestive Diseases Centre, Faculty of Medicine and Health Sciences, \\ University of Nottingham, E. Floor West Block, Queen's Medical Centre, Derby Road, Nottingham NG7 2UH, UK \\ ${ }^{2}$ Research \& Development Department, Lincoln Breast Unit, Lincoln County Hospital, Greetwell Road, Lincoln LN2 5QY, UK \\ ${ }^{3}$ Department of Pathology, Path Links, Lincoln County Hospital, Greetwell Road, Lincoln LN2 5QY, UK \\ ${ }^{4}$ Academic Department of Pathology, Faculty of Medicine and Health Sciences, University of Nottingham, A Floor West Block, \\ Queen's Medical Centre, Derby Road, Nottingham NG7 2UH, UK \\ ${ }^{5}$ Department of Surgery, Phramongkutklao Hospital and College of Medicine, 315 Rajavithi Road, Bangkok 10400, Thailand
}

Correspondence should be addressed to Viriya Kaewkangsadan; kaewkangsadan@yahoo.co.uk

Received 19 April 2017; Accepted 25 July 2017; Published 23 August 2017

Academic Editor: Douglas C. Hooper

Copyright (C) 2017 Viriya Kaewkangsadan et al. This is an open access article distributed under the Creative Commons Attribution License, which permits unrestricted use, distribution, and reproduction in any medium, provided the original work is properly cited.

\begin{abstract}
The tumour microenvironment consists of malignant cells, stroma, and immune cells. The role of adaptive immunity in inducing a pathological complete response (pCR) in breast cancer with neoadjuvant chemotherapy (NAC) is well studied. The contribution of innate immunity, however, is poorly documented. Breast tumours and axillary lymph nodes (ALNs) from 33 women with large and locally advanced breast cancers (LLABCs) undergoing NAC were immunohistochemically assessed for tumour-infiltrating macrophages (TIMs: M1 and M2), neutrophils (TINs), and dendritic cells (TIDCs) using labelled antibodies and semiquantitative methods. Patients' blood neutrophils $(n=108)$, DCs (mDC1 and pDC), and their costimulatory molecules $(n=30)$ were also studied. Pathological results were classified as pCR, good (GPR) or poor (PRR). In breast and metastatic ALNs, high levels of $\mathrm{CD}_{163^{+}}$TIMs were significantly associated with a pCR. In blood, high levels of neutrophils were significantly associated with pCR in metastatic ALNs, whilst the \% of $\mathrm{mDC} 1$ and pDC and expression of HLA-DR, mDC1 CD40, and CD83 were significantly reduced. NAC significantly reduced tumour DCs but increased blood DCs. PPRs to NAC had significantly reduced HLA-DR, CD40, and CD86 expression. Our study demonstrated novel findings documenting the differential but important contributions of innate immunity to pCRs in patients with LLABCs undergoing NAC.
\end{abstract}

\section{Background}

Anticancer immune mechanisms play an important role in the induction, development, and dissemination of malignant disease in man [1-4]. Both innate and adaptive immune cells have been documented in various human cancers (breast, gastrointestinal, urogenital, head and neck, and melanoma), and the presence of a prominent lymphocytic infiltrate is associated with a good clinical outcome [4-8]. In women with breast cancer undergoing neoadjuvant chemotherapy (NAC), the presence of a high level of tumour-infiltrating lymphocytes (TILs) has been shown to be an independent 
predictor of a complete pathological response ( $\mathrm{pCR}$ ) in the breast tumour [9-13]. The presence of TILs infiltrating axillary lymph node (ALN) metastases and their association with a pCR, however, is less well studied (Kaewkangsadan et al., 2016b submitted for publication).

The role of adaptive immunity ( $\mathrm{T}$ effector and regulatory cells, $\mathrm{T}$ helper (Th), and suppressor cytokines) in women with breast cancer undergoing NAC has been investigated in primary breast tumours, but much less so in tumour-draining ALNs. Significant associations have been documented between high levels of infiltration by $\mathrm{T}$ effector cells $\left(\mathrm{CD}^{+}\right.$and $\left.\mathrm{CD}^{+}\right)$and low levels of $\mathrm{T}$ regulatory cells (Tregs: $\mathrm{FOXP}^{+}$(forkhead box protein 3 ) and CTLA- $4^{+}$(cytotoxic T lymphocyte antigen-4)) and subsequent pCRs with NAC in primary breast tumours and ALN metastases [13-17]; (Kaewkangsadan et al., 2016b submitted for publication). The contribution from innate immunity (natural killer (NK) cells, macrophages, neutrophils, and dendritic cells (DCs)) to breast cancer cell death during NAC, however, is less well studied and poorly documented.

We have recently described the key role played by NK cells within primary breast tumours and tumour-draining ALNs. Our studies have shown a significant association between high levels of tumour-infiltrating $\mathrm{CD}^{2} 6^{+} \mathrm{NK}$ cells, in both the primary tumours and ALN metastases, and subsequent pCRs with NAC. These findings highlight the important contribution of innate immunity to immunemediated tumour cell death in patients with breast cancer undergoing NAC.

Macrophages are terminally differentiated myeloid cells, closely related to DCs, and are resident in tissues. Human solid tumours recruit macrophages into their microenvironment. Breast cancers, in particular, contain a substantial number of macrophages [18]. Clinical and experimental evidence indicate that tumour-infiltrating macrophages (TIMs) play a major role in the initiation, progression, and dissemination of malignant disease [19]. Two main polarised phenotypes (M1 and M2) have been described. High levels of TIMs in most cancers, including breast cancer, are associated with a poor disease-free survival (DFS) and overall survival (OS) [20-23]. Heys et al. described high levels of the M1 CD68 ${ }^{+}$TIMs in breast cancers. [24]. Therefore, the association between M2 $\mathrm{CD}_{163^{+}}$TIMs and tumour response to NAC in both the breast and ALNs was examined.

Polymorphonuclear leukocytes (neutrophils) play a crucial role in dealing with invading pathogens and assist in wound healing. They release a range of toxic substances (reactive oxygen species and proteinases) to deal with invading microorganisms [25]. Increased levels of circulating neutrophils have been documented in patients with various solid cancers (breast, colon, pancreas, head and neck, and melanoma) in the absence of overt infection and inflammation. They have been shown to be immature, producing low levels of free radicals and showing impaired intracellular killing of pathogens [26]. Increased levels in blood in various solid cancers have been shown to be associated with poor clinical outcome [26]. Neutrophils are recruited into the tumour milieu by chemotactic stimuli from macrophages and tumour cells and have been described modifying tumour growth and invasiveness [27-29]. The presence of $\mathrm{CD}^{2} \mathrm{~b}^{+}$tumour-infiltrating neutrophils (TINs) has been shown to be associated with a reduced DFS and OS in human cancers (renal, head and neck, hepatic, and melanoma) [30-33]. There is a dearth of data on the significance of TINs in LLABCs and the interaction with NAC and possible tumour pCR. In this study, we have investigated the association between TINs and subsequent pCR with NAC in both the primary tumour and ALN metastases, and concurrently, neutrophils in the circulation.

Dendritic cells (DCs) are derived from haematopoietic progenitor cells in the bone marrow, monocytes being major precursor cells. They are crucial antigen-presenting cells, initiating and directing adaptive immune responses [34]. Various types have been categorised according to their morphological characteristics, phenotypic profiles, and in situ residence. Two main types, the large myeloid-derived $\mathrm{DC}(\mathrm{mDC})$ and the small plasmacytoid DC (pDC), upregulate the expression of coregulatory and costimulatory molecules (HLA-DR, CD40, CD80, and CD86) and the lymph node homing (LNH) molecules (CD197), enhancing adaptive immunity [35-37].

Various factors, including tumour stroma-released chemokines and cytokines (CCL19 and transforming growth factor- $\beta$ (TGF- $\beta$ )), hypoxia, and prostaglandins (PGE2), act as chemoattractants and induce DC recruitment into the tumour microenvironment [38]. DCs have been shown to infiltrate various types of human tumours [39]. In breast cancer, there is evidence that DCs in the tumour microenvironment are present in very low numbers and are poorly activated [40-42]. Moreover, dysfunctional DCs (suppressive and tolerogenic) have been identified in the circulation and tumour-draining ALNs in patients with operable breast cancer $[38,43]$. Coventry et al. demonstrated a nonsignificant-enhanced 5-year survival rate in patients with breast cancer whose tumours had high levels of infiltration by $\mathrm{CD}_{1} \mathrm{a}^{+}$DCs [44]. There is no published data on the significance and effect of circulating and TIDCs on pCR with NAC in breast cancer. We have investigated this in the blood, breast, and ALNs in the current study.

We have recently documented, in women with LLABCs undergoing $\mathrm{NAC}$, that a significant reduction of both circulating and tumour-infiltrating Tregs $\left(\mathrm{FOXP}^{+}, \mathrm{CTLA}-4^{+}\right)$ and high levels of TILs and $\mathrm{CD} 8^{+} \mathrm{T}$ cells in the primary and ALN metastatic tumours were significantly associated with subsequent pCRs [13]; (Kaewkangsadan et al., 2016b submitted for publication). We also demonstrated that high $\mathrm{CD}^{+}: \mathrm{FOXP}^{+} \mathrm{T}$ cell ratios in the primary breast tumours and metastatic ALNs (tumour-free paracortex) were significantly associated with pCRs, highlighting the close and complex interrelationships between NAC and adaptive immunity. Furthermore, we recently described the important relationship between NK cells (blood, tumour, and ALNs), a key component of innate immunity, and NAC and pCR responses [45]. We have studied further the role of other 
components (TIMs, neutrophils, and DCs (blood and tumour)) of innate immunity in women with LLABCs undergoing NAC and their possible contribution to the pCRs that occur with chemotherapy and document our novel findings in this article.

\section{Materials and Methods}

2.1. Patients and Samples. Paraffin-embedded sections of breast tumours and tumour-draining ALNs from 33 women with large (L: $\geq 3 \mathrm{~cm})$ and locally advanced breast cancers (LABCs: T3, 4; N1, 2; M0), enrolled in a study of NAC (108 patients enrolled between 2008 and 2011), were studied [46]. Histological diagnosis was established from ultrasoundguided core biopsies. To minimise tumour heterogeneity and sampling discrepancies, several core biopsies were obtained from each tumour. All tumours prior to NAC had a radiopaque coil inserted. Post-NAC, wire-guided removal of the residual "tumour" was carried out (in the case of breast conservation) if there was no clinical or radiological evidence of cancer. Operative specimens (wide local excision and mastectomy) had radiological confirmation of the presence of the coil to ensure accurate localisation and histopathological evaluation. Twenty-four patients had nodal metastases, and 9 patients were without nodal metastases; 20 out of 24 patients with nodal metastases had additional pre-NAC ultrasound-guided core needle biopsy samples of metastatic tumours in ALNs. Representative tissue sections were used for immunohistochemical (IHC) evaluation. All pre- and post-NAC specimens were discussed at a multidisciplinary meeting and a consensus reached about the pathological response and treatment options.

The NAC trial evaluated the effect of the addition of capecitabine $(\mathrm{X})$ to docetaxel $(\mathrm{T})$ preceded by adriamycin and cyclophosphamide (AC). Pathological responses were assessed in the excised surgical specimens after NAC. Established and previously published grading criteria were used to define histopathological responses in the breast [47, 48]. Good pathological responses were graded 5 (pCR, no residual invasive disease) and 4 ( $\geq 90 \%$ loss of invasive disease). Patients with grade 5 and 4 responses constituted the good pathological responders (GPRs). Poor pathological responses were graded as 3 (30-90\% loss of invasive disease), $2(<30 \%$ loss of invasive disease), and 1 (no loss of tumour cells). Patients with these responses constituted the PPR group. Pathological responses in metastatic tumours in ALNs were defined as pCR (grade 3: complete disappearance of tumour deposits or replacement by fibrosis in a previously histologically confirmed metastatic ALN); pathological partial response (grade 2: residual metastatic tumour deposits present with evidence of tumour destruction and replacement by fibrosis); and no pathological response (grade 1: metastatic tumour deposits remain with no evidence of fibrosis). Patient cases were randomly selected based on availability of tissue specimens and to ensure an even distribution between compared groups (pCR versus non-pCR).

The study was given approval by the Leicestershire, Northamptonshire \& Rutland Research Ethics Committee 1: Reference number 07/H0406/260; Favourable Opinion
24/01/2008. All patients enrolled in the study gave informed consent to participate in and to publish the results of the study. The study registration is ISRCTN00407556.

2.2. Blood DC Phenotyping. Venous blood samples were collected before $(n=30)$ and following completion of NAC $(n=16)$. These blood samples were from the same patients whose tumour and nodal specimens were investigated immunohistochemically for $\mathrm{CD} \mathrm{a}^{+} \mathrm{DCs}$. Venous blood samples were also collected from 10 age-and sex-matched healthy female donors (HFDs) to establish normal values. Peripheral blood mononuclear cells (PBMCs) were isolated by centrifugation on Ficoll-Hypaque, washed and made up in RPMI with $10 \%$ foetal calf serum (FCS) (Sigma, UK) and antibiotics (TCM), and stored at $-80^{\circ} \mathrm{C}$ for further analysis.

The $\mathrm{mDC} 1^{\text {high }}\left(\mathrm{Lin1}^{-}, \mathrm{HLA}-\mathrm{DR}^{+}, \mathrm{CD} 11 \mathrm{c}^{+}\right.$, and $\left.\mathrm{CD} 1 \mathrm{c}^{+}\right)$ and the $\mathrm{pDC}^{\text {high }}\left(\mathrm{Lin1}^{-}, \mathrm{HLA}-\mathrm{DR}^{+}, \mathrm{CD} 11 \mathrm{c}^{+}\right.$, and $\left.\mathrm{CD}^{-} 3^{+}\right)$ subsets and their costimulatory molecules were documented in $2 \times 10^{6}$ cells $/ 100 \mu \mathrm{l}$ of PBMCs and stained for cell surface markers for 30 minutes (mins) with $5 \mu$ l fluorescein isothiocyanate (FITC) anti-human LIN1, $5 \mu \mathrm{l}$ Texas red conjugate (ECD) anti-human HLA-DR, $5 \mu$ l Pacific Blue anti-human CD11c, $5 \mu \mathrm{l}$ allophycocyanin (APC) Cy7 anti-human CD40, $5 \mu \mathrm{l}$ Pe-Cy7 anti-human CD80, $5 \mu \mathrm{l}$ APC antihuman CD86, $5 \mu \mathrm{l}$ Alexa 700 anti-human CD197, $2.5 \mu \mathrm{l}$ Percp-fluor-710 anti-human CD1c (BDCA-1) for mDCs ${ }^{\text {high }}$, and $5 \mu \mathrm{l}$ CD303-PE (BDCA-2) for $\mathrm{pDCs}^{\text {high }}$ which were added to the corresponding tubes and incubated for $30 \mathrm{mins}$ at $4^{\circ} \mathrm{C}$. The PBMC pellet was washed twice in phosphatebuffered saline. The PBMCs were then resuspended in 400 $\mu \mathrm{l}$ of $0.5 \%$ paraformaldehyde fixative solution for flow cytometric analysis on a Beckman Coulter FC500.

Blood neutrophil counts (pre- and post-NAC) in 108 women with LLABC were collected and used in the analysis to evaluate association with NAC-induced $\mathrm{pCR}$ in the breast and tumour-draining ALNs.

2.3. Immunohistochemical (IHC) Assessment. Immunohistochemical assessments of immune cell subsets and expression of indoleamine 2,3-dioxygenase (IDO) and vascular endothelial growth factor (VEGF) were performed in $4 \mu \mathrm{m}$ tissue sections. Briefly, paraffin-embedded tissue sections were dewaxed and rehydrated using xylene and graded alcohol. Citrate buffer, $\mathrm{pH} 6.0$, at $98^{\circ} \mathrm{C}$ was added for 20 mins for antigen retrieval. After serial blocking, the sections were incubated with the primary monoclonal antibody (MAb) against CD68 (Abcam, ab955, clone KP1), 1:300 dilution for 30 mins at room temperature (RT); MAb against CD163 (Abcam, ab74604, clone 10D6), prediluted for 30 mins at RT; MAb against CD1a (Dako, M3571, clone 010), 1:200 dilution for 15 mins at RT; MAb against CD66b (LS Bio, LS-B7134, clone $80 \mathrm{H} 3), 10 \mu \mathrm{g} / \mathrm{ml}$ for 30 mins at RT; MAb against IDO (Abcam, ab55305), $0.75 \mu \mathrm{g} / \mathrm{ml}$ for $15 \mathrm{mins}$ at RT; and MAb against VEGF (Dako, M7273, clone VG1), $1: 50$ dilution for 30 mins at RT. The Novolink ${ }^{\mathrm{TM}}$ polymer detection system, Leica RE7280-K with polymeric horseradish peroxidase- (HRP-) linker antibody conjugates and diaminobenzidine (DAB) chromogen, was used for enzymesubstrate labelling. Finally, the sections were counterstained 
TABLE 1: Analyses of tumour-infiltrating $\mathrm{CD}^{+} 8^{+}$and $\mathrm{CD} 163^{+}$macrophages in the breast tumours in women with LLABCs and subsequent PCR following NAC.

\begin{tabular}{|c|c|c|c|c|c|}
\hline \multirow[b]{2}{*}{ Macrophages } & \multirow[b]{2}{*}{ Groups } & \multicolumn{4}{|c|}{ Pre-NAC } \\
\hline & & Low infiltration $(n)$ & High infiltration $(n)$ & $\begin{array}{l}\text { Pearson chi-square value (GPR versus } \\
\text { PPR, PCR versus non-PCR) }\end{array}$ & $p$ value \\
\hline \multirow{4}{*}{$\begin{array}{l}\mathrm{CD}^{+} 8^{+} \\
(n=16)\end{array}$} & $\begin{array}{l}\text { Good pathological response } \\
\qquad(\mathrm{GPR}, n=9)\end{array}$ & 5 & 4 & \multirow{2}{*}{1.667} & \multirow{2}{*}{0.197} \\
\hline & $\begin{array}{l}\text { Poor pathological response } \\
\qquad(\mathrm{PPR}, n=7)\end{array}$ & 6 & 1 & & \\
\hline & $\begin{array}{l}\text { Pathological complete response } \\
\qquad(\mathrm{PCR}, n=6)\end{array}$ & 3 & 3 & \multirow{2}{*}{1.571} & \multirow{2}{*}{0.210} \\
\hline & $\begin{array}{l}\text { Nonpathological complete } \\
\text { response (non-PCR, } n=10 \text { ) }\end{array}$ & 8 & 2 & & \\
\hline \multirow{4}{*}{$\begin{array}{l}\mathrm{CD}_{163} 3^{+} \\
(n=33)\end{array}$} & $\begin{array}{l}\text { Good pathological response } \\
\qquad(\mathrm{GPR}, n=21)\end{array}$ & 5 & 16 & \multirow{2}{*}{8.192} & \multirow{2}{*}{$0.004^{*}$} \\
\hline & $\begin{array}{l}\text { Poor pathological response } \\
\qquad(\mathrm{PPR}, n=12)\end{array}$ & 9 & 3 & & \\
\hline & $\begin{array}{l}\text { Pathological complete response } \\
\text { (PCR, } n=16)\end{array}$ & 3 & 13 & \multirow{2}{*}{7.127} & \multirow{2}{*}{$0.008^{*}$} \\
\hline & $\begin{array}{l}\text { Nonpathological complete } \\
\text { response (non-PCR, } n=17 \text { ) }\end{array}$ & 11 & 6 & & \\
\hline
\end{tabular}

LLABCs: large and locally advanced breast cancers; NAC: neoadjuvant chemotherapy; * statistically significant.

with haematoxylin, dehydrated, and mounted in DPX mounting medium. Positive and negative staining controls were carried out with tonsil sections except for CD163 (liver sections) and IDO (normal colon sections). Negative staining controls were demonstrated by omitting the primary antibody. Positive and negative controls were simultaneously performed with every IHC staining run. All primary antibodies used in this study have been validated and certified by the commercial suppliers for IHC assessment of paraffinembedded specimens.

2.4. Semiquantification of IHC Sections. Whole tissue sections were studied rather than microarrays (to minimise sampling bias). The majority of macrophages present in breast tumours were located along the border of tumour nests. Immunostaining for TIMs was evaluated along the tumour front (TF) over the whole section (7-10 view fields per section). This evaluation followed previously published studies documenting the level of TIMs [49-51]. Tumour tissue containing small areas of prominent infiltration of $\mathrm{CD}^{+} 8^{+}$or $\mathrm{CD}_{163}{ }^{+}$cells, which was considerably higher than the average level of $\mathrm{CD}^{+} 8^{+} / \mathrm{CD} 63^{+}$cells, was defined as hotspots (TF hotspot). All sections were evaluated at a distance away from areas of necrosis. The TF hotspots of the two view fields with the highest measurements at $\times 200$ magnification were averaged out (CD68 or CD163 TF mean). The average infiltration (CD68 or CD163 TF mean) was semiquantitatively graded as no/weak (grade 1), moderate (grade 2), strong/ robust (grade 3), and massive infiltration (grade 4). Tumours classified as 1 included totally negative specimens as well as specimens containing some scattered positively stained cells along the tumour margin. Tumours were classified as 2 when CD68 or CD163 staining was continuous along the tumour margin but did not extend from the tumour front for more than one cell layer on average. CD68 or CD163 staining that, on average, extended two to three cell layers from the tumour margin over the whole section was classified as 3; CD68 or CD163 staining extending more than three cell layers from the tumour margin in all fields was classified as 4 . For statistical analysis, grades 1 and 2 were defined as low level of infiltration whereas grades 3 and 4 were defined as high level of infiltration [49-51].

To evaluate the presence and extent of $\mathrm{CDla}^{+}$and $\mathrm{CD} 6 \mathrm{~b}^{+}$cells in the breast tumours, the average numbers of brown membrane-stained cells regardless of the intensity were counted in 5 high-power fields (400x HPFs). Positively stained cells in contact with tumour cells or within the tumour cell nests were defined as "intratumoural" whereas positively stained cells in the interstitial stroma surrounding tumour nests were defined as "peritumoural/stromal." Evaluation of infiltrations in post-NAC specimens was undertaken on residual tumour nests, and in the case of pCR (complete disappearance of invasive tumour cells in the specimen), in the tumour bed. The latter was characterised histologically as a hyalinised, amorphous area with haemosiderin deposits $[52,53]$.

Positively stained macrophages $\left(\mathrm{CD} 68^{+}\right.$and $\left.\mathrm{CD} 163^{+}\right)$in ALNs were quantified as the average \% of all cells in 5 HPFs in nonmetastatic medullary areas of ALNs. The average number of cell counts in 5 HPFs in nonmetastatic areas with the greatest accumulations of positively stained cells on scanning at low magnification was determined for $\mathrm{CD} 6 \mathrm{~b}^{+}$and $\mathrm{CD}^{+}{ }^{+}$cells. These quantitative evaluations followed the methodological scoring for documenting various immune cell subsets present in ALNs in patients with breast cancer [42, 54].

To evaluate the presence of IDO and VEGF, the semiquantitative $\mathrm{H}$ scoring system was employed using whole tissue sections. The $\mathrm{H}$ score was calculated by multiplying the $\%$ of positive cells (tumour and immune) by a factor 


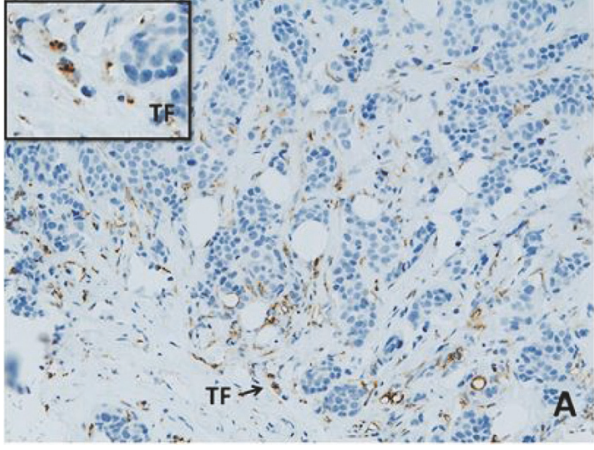

(a)

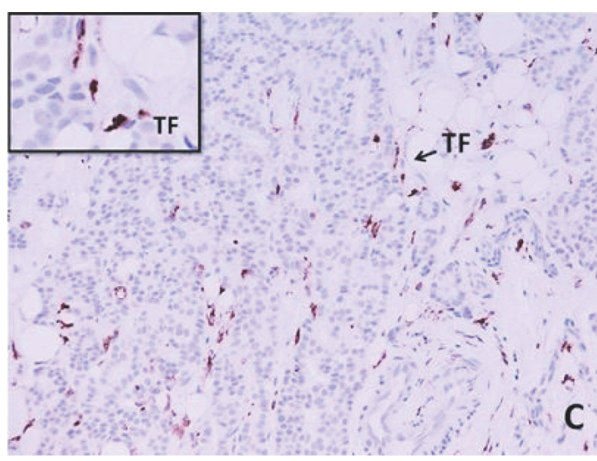

(c)

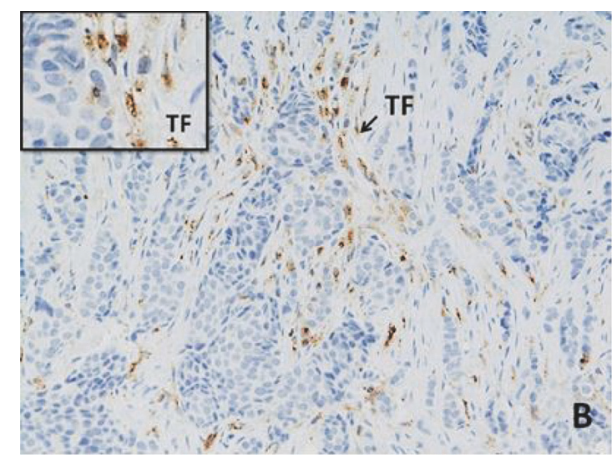

(b)

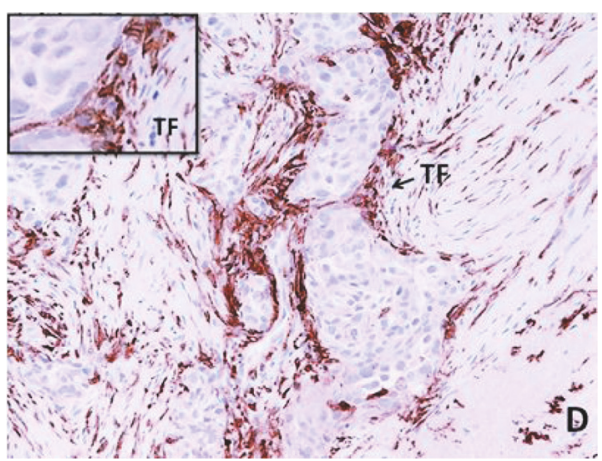

(d)

Figure 1: $\mathrm{CD}^{+} 8^{+}(\mathrm{a}, \mathrm{b})$ and $\mathrm{CD}_{163}{ }^{+}(\mathrm{c}, \mathrm{d})$ macrophages in the sections of LLABCs, using IHC staining, at 200x magnification. Briefly, heatmediated antigen retrieval was performed using citrate buffer, $\mathrm{pH} 6$ (20 mins). The sections were then incubated with MAbs to CD68 (Abcam, ab955) at a 1:300 dilution for 30 mins at RT, MAbs to CD163 (Abcam, ab74604) at a prediluted concentration for 30 mins at RT. Polymeric HRP-linker antibody conjugate was used as secondary antibody. DAB chromogen was used to visualize the staining. The sections were counterstained with haematoxylin. (a, c) Low level of $\mathrm{CD} 8^{+}$and $\mathrm{CD}_{163^{+}}$macrophage infiltration; (b, d) high level of $\mathrm{CD} 68^{+}$and $\mathrm{CD} 63^{+}$macrophage infiltration. Tumours were classified as low level of infiltration when the positively brown membrane-stained cells were scattered or continuous along the tumour margin but did not extend from the tumour front (TF) for more than one cell layer. Extension for two or more layers from the TF was classified as a high level of infiltration.

TABLE 2: Alteration of tumour-infiltrating $\mathrm{CD}^{+} 8^{+}$and $\mathrm{CD} 163^{+}$macrophages in the breast tumours in women with LLABCs undergoing NAC.

\begin{tabular}{|c|c|c|c|c|c|}
\hline \multirow{2}{*}{ Macrophages } & & \multirow{2}{*}{ Groups } & \multicolumn{2}{|c|}{ Post-NAC } & \multirow{2}{*}{$p$ value $^{(3)}$ (pre- versus post-NAC) } \\
\hline & & & Low infiltration $(n)$ & High infiltration $(n)$ & \\
\hline \multirow{2}{*}{$\mathrm{CD} 8^{+}(n=16)$} & \multirow{2}{*}{ Pre-NAC } & Low infiltration $(n)$ & 10 & 1 & \multirow{2}{*}{0.375} \\
\hline & & High infiltration $(n)$ & 4 & 1 & \\
\hline \multirow{2}{*}{$\mathrm{CD} 163^{+}(n=16)$} & \multirow{2}{*}{ Pre-NAC } & Low infiltration $(n)$ & 4 & 2 & \multirow{2}{*}{0.289} \\
\hline & & High infiltration $(n)$ & 6 & 4 & \\
\hline
\end{tabular}

LLABCs: large and locally advanced breast cancers; NAC: neoadjuvant chemotherapy; ${ }^{(3)}$ related sample McNemar test.

representing the intensity of immune reactivity ( 1 for weak, 2 for moderate, and 3 for strong), giving a maximum score of 300. A score of $<50$ was considered negative, and a score of 50-100 was considered weakly positive $(1+)$. A score of 101-200 was regarded as moderately positive (2+) and a score of 201-300 as strongly positive (3+). Negative and $1+$ were considered as low expression whereas $2+$ and $3+$ were considered as high expression $[55,56]$.

All scored assessments were performed without the knowledge of the patients' clinical and pathological parameters. The pathological responses were assessed by a consultant breast pathologist. The scoring systems used in establishing the biological markers present in breast tumours and metastatic tumours in ALNs, and ALNs in this investigation, followed previously published studies documenting the scoring systems employed (described above).

2.5. Statistical Analysis. Statistical analyses were performed with the IBM SPSS statistics software, version 21 (SPSS Inc., Chicago, IL, USA). Where the data did not follow a normal distribution, a nonparametric test (Mann-Whitney $U$ test (between two variables/groups)) was used to compare the groups based on pathological responses. The Pearson chisquare test was performed to compare the binomial data 
TABLE 3: Analyses of $\mathrm{CD}_{163^{+}}$macrophages in metastatic tumours in ALNs in women with LLABCs and subsequent PCR following NAC.

\begin{tabular}{lccc}
\hline & Groups & Pre-NAC & \\
& Low infiltration $(n)$ & High infiltration $(n)$ & $\begin{array}{c}\text { Pearson chi-square value } \\
(\text { PCR versus non-PCR })\end{array}$ \\
$p$ value
\end{tabular}

ALNs: axillary lymph nodes; LLABCs: large and locally advanced breast cancers; NAC: neoadjuvant chemotherapy; *statistically significant.

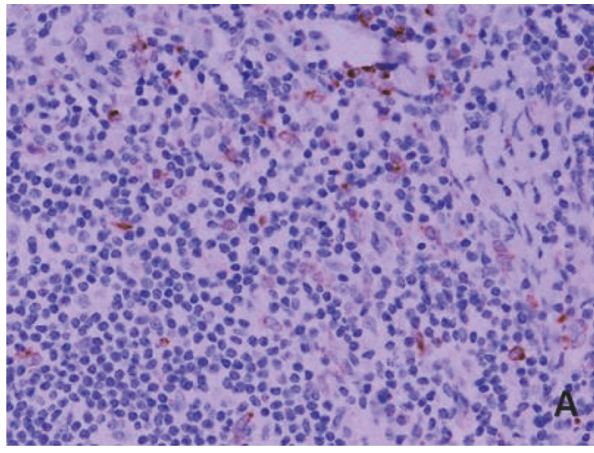

(a)

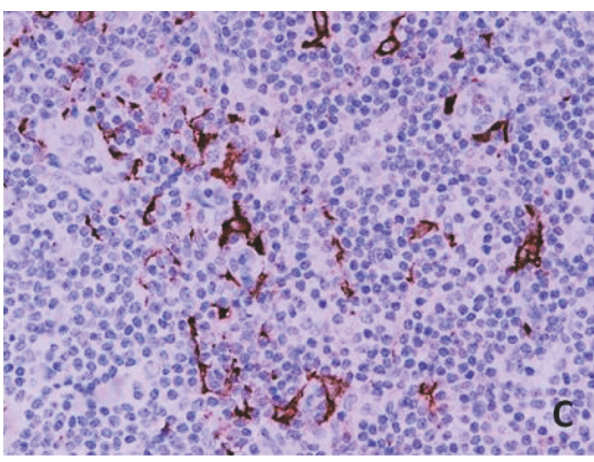

(c)

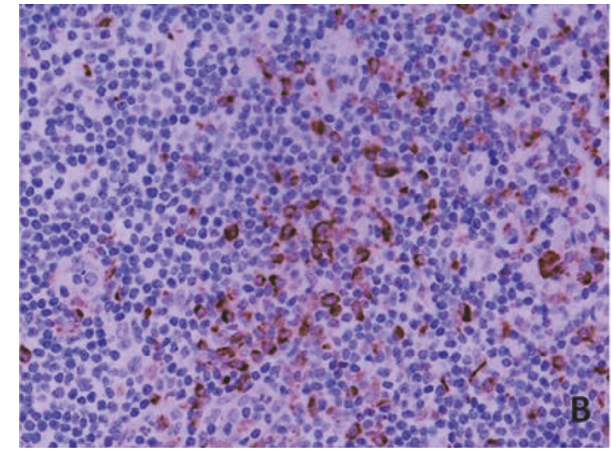

(b)

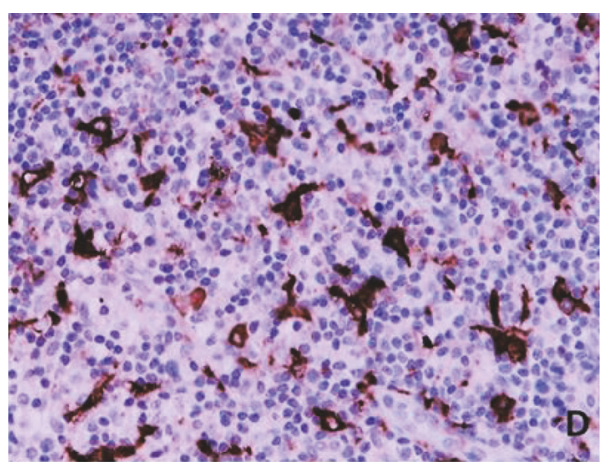

(d)

FIgure 2: $\mathrm{CD}^{+}(\mathrm{a}, \mathrm{b})$ and $\mathrm{CD}^{+} 3^{+}(\mathrm{c}, \mathrm{d})$ macrophages in the sections of axillary lymph nodes (ALNs), using IHC staining, at 400x magnification. Briefly, heat-mediated antigen retrieval was performed using citrate buffer, pH 6 (20 mins). The sections were then incubated with MAbs to CD68 (Abcam, ab955) at a 1:300 dilution for 30 mins at RT, MAbs to CD163 (Abcam, ab74604) at a prediluted concentration for 30 mins at RT. Polymeric HRP-linker antibody conjugate was used as secondary antibody. DAB chromogen was used to visualize the staining. The sections were counterstained with haematoxylin. (a, c) Low percentage of $\mathrm{CD} 68^{+}$and $\mathrm{CD} 163^{+}$ macrophages; (b, d) high percentage of $\mathrm{CD}^{+} 8^{+}$and $\mathrm{CD} 163^{+}$macrophages. The positive brown membrane-stained cells in tumour-free medullary areas of ALNs were quantified as the average \% of all cells (5 HPFs).

(negative/low versus high) on level of TIMs and expression of IDO/VEGF between groups. To evaluate and compare the related sample data between pre-NAC and post-NAC groups, as well as primary breast tumours and metastatic tumours in ALNs, the related sample Wilcoxon signed-rank test and related sample $\mathrm{McNemar}$ test were performed for comparing the number of cell counts and the expression of IDO/VEGF, respectively. A probability value ( $p$ value) of equal to or less than 0.05 (2 tailed) was considered statistically significant.

The sample size of this study was based on a cohort of patients from a previous study in which circulating Tregs were documented pre- and post-NAC [57]. A sample size of at least 7 in each group having an $80 \%$ power to detect a difference between two groups with $p$ values of $\leq 0.05$ (two sided) was calculated by assuming the common standard deviation of circulating blood Tregs as 0.5 . As our findings are derived from several assays of different parameters, the sample size of at least 7 in each group may not be optimal for some of the tests. In addition, multiple hypothesis testing may lower the significance of our findings.

\section{Results}

3.1. Patient and Tumour Characteristics and Responses to NAC. The patient and tumour characteristics of the 33 
TABLE 4: Comparison of $\mathrm{CD} 163^{+}$macrophages between primary breast tumours and ALN metastatic tumours in women with LLABCs.

\begin{tabular}{|c|c|c|c|c|c|}
\hline \multirow{2}{*}{ Groups } & & & \multicolumn{2}{|c|}{ Metastatic tumours in ALNs } & \multirow{2}{*}{$\begin{array}{c}p \text { value }^{(3)} \text { (primary versus } \\
\text { metastases) }\end{array}$} \\
\hline & & & Low infiltration $(n)$ & High infiltration $(n)$ & \\
\hline \multirow{2}{*}{$\begin{array}{l}\mathrm{CD} 163^{+} \\
\text {macrophages }\end{array}$} & \multirow{2}{*}{$\begin{array}{c}\text { Primary tumours in } \\
\text { breast }\end{array}$} & $\begin{array}{l}\text { Low infiltration } \\
\qquad(n)\end{array}$ & 6 & 2 & \multirow{2}{*}{1.000} \\
\hline & & $\begin{array}{c}\text { High infiltration } \\
(n)\end{array}$ & 1 & 11 & \\
\hline
\end{tabular}

ALN: axillary lymph node; LLABCs: large and locally advanced breast cancers; ${ }^{(3)}$ related sample McNemar test.

TABLE 5: Analyses of tumour-infiltrating CD1a ${ }^{+}$dendritic cells and $\mathrm{CD}_{6} 6 \mathrm{~b}^{+}$neutrophils in the breast tumours in women with LLABCs and subsequent PCR following NAC.

\begin{tabular}{|c|c|c|c|c|c|}
\hline $\begin{array}{l}\text { Cell } \\
\text { subsets }\end{array}$ & Groups & $\begin{array}{c}\text { Pre-NAC } \\
\text { intratumoural } \\
\text { median (range) }\end{array}$ & $\begin{array}{c}p \text { value }^{(3)}(\mathrm{GPR} \text { versus } \\
\text { PRR, PCR versus } \\
\text { non-PCR }) \\
\end{array}$ & $\begin{array}{c}\text { Pre-NAC } \\
\text { peritumoural median } \\
(\text { range })^{(3)}\end{array}$ & $\begin{array}{l}p \text { value }^{(4)}(\mathrm{GPR} \text { versus } \mathrm{PRR}, \\
\text { PCR versus non-PCR) }\end{array}$ \\
\hline \multirow{4}{*}{$\begin{array}{l}\mathrm{CD} \mathrm{a}^{+} \\
(n=16)\end{array}$} & $\begin{array}{l}\text { Good pathological response } \\
\qquad(\mathrm{GPR}, n=9)\end{array}$ & $3(1-104)$ & \multirow{2}{*}{0.837} & $1(1-16)$ & \multirow{2}{*}{0.837} \\
\hline & $\begin{array}{l}\text { Poor pathological response } \\
\qquad(\mathrm{PPR}, n=7)\end{array}$ & $11(0-63)$ & & $2(0-11)$ & \\
\hline & $\begin{array}{l}\text { Pathological complete } \\
\text { response }(\mathrm{PCR}, n=6)\end{array}$ & $3(1-104)$ & \multirow{2}{*}{0.713} & $1.5(1-16)$ & \multirow[b]{2}{*}{0.492} \\
\hline & $\begin{array}{l}\text { Nonpathological complete } \\
\text { response (non-PCR, } n=10 \text { ) }\end{array}$ & $4(0-63)$ & & $1.5(0-11)$ & \\
\hline \multirow{4}{*}{$\begin{array}{l}\mathrm{CD} 6 \mathrm{~b}^{+} \\
(n=16)\end{array}$} & $\begin{array}{l}\text { Good pathological response } \\
\qquad(\mathrm{GPR}, n=9)\end{array}$ & $2(0-53)$ & \multirow{2}{*}{0.174} & $2(0-71)$ & \multirow{2}{*}{0.408} \\
\hline & $\begin{array}{l}\text { Poor pathological response } \\
\qquad(\mathrm{PPR}, n=7)\end{array}$ & $1(0-3)$ & & $1(0-2)$ & \\
\hline & $\begin{array}{l}\text { Pathological complete } \\
\text { response (PCR, } n=6)\end{array}$ & $3(0-53)$ & \multirow{2}{*}{0.181} & $5(0-71)$ & \multirow{2}{*}{0.118} \\
\hline & $\begin{array}{l}\text { Nonpathological complete } \\
\text { response (non-PCR, } n=10 \text { ) }\end{array}$ & $1(0-3)$ & & $1(0-2)$ & \\
\hline
\end{tabular}

LLABCs: large and locally advanced breast cancers; NAC: neoadjuvant chemotherapy; ${ }^{(3)}$ total cell count per 5 high-power fields (core biopsies of breast cancers); ${ }^{(4)}$ Mann-Whitney $U$ test.

patients studied are shown in Table A (Supplementary Table available online at https://doi.org/10.1155/2017/1049023). The responses to NAC and the tumour recurrence and survival at 4 years of follow-up are documented.

3.2. High Levels of Infiltration of Breast Tumours in LLABCs by $\mathrm{CD} 8^{+}$and $\mathrm{CD} 63^{+}$Macrophages and Subsequent PCR with NAC. High levels of $\mathrm{CD}_{163}{ }^{+}$TIMs in breast cancers were significantly associated with a GPR and pCR $(p=0.004, p=0.008)$, respectively, following 8 cycles of NAC. There was, however, no significant association between $\mathrm{CD}^{+} 8^{+}$TIMs and GPR and pCR with NAC (Table 1). Figure 1 illustrates the presence of high and low levels of infiltration by $\mathrm{CD}^{+} 8^{+}$(Figures 1(a) and 1(b)) and $\mathrm{CD} 163^{+}$macrophages (Figures $1(\mathrm{c})$ and $1(\mathrm{~d})$ ) in the primary tumours.

Eight cycles of NAC, on the other hand, did not alter the level of infiltration by $\mathrm{CD}^{+} 8^{+}$and $\mathrm{CD}_{163}{ }^{+}$TIMs in postNAC tumour specimens when compared with pre-NAC specimens (Table 2).

3.3. High Levels of Infiltration of ALN Metastases in LLABCs by $\mathrm{CD}_{163^{+}}$Macrophages and Subsequent PCR with NAC. High levels of $\mathrm{CD}_{163^{+}}$TIMs in metastatic deposits in tumour-draining ALNs were significantly associated with a pCR $(p=0.003)$. As the levels of $\mathrm{CD}^{+} 8^{+}$TIMs in primary tumours showed no association with a pCR following NAC, we elected not to study this subset in the ALN metastases (Table 3). Figure 2 illustrates $\mathrm{CD}^{+}{ }^{+}$(Figures 2(a) and 2(b)) and $\mathrm{CD}_{163^{+}}$macrophages (Figures $2(\mathrm{c})$ and $\left.2(\mathrm{~d})\right)$ in the ALNs (tumour-free medullary areas).

Comparison of primary breast cancers with ALN metastases showed no significant differences in the levels of infiltration by $\mathrm{CD}_{163^{+}}$TIMs (Table 4 ).

3.4. Tumour Infiltration of Breast Tumours in LLABCs by $\mathrm{CD} \mathrm{a}^{+}$DCs and CD66b ${ }^{+}$Neutrophils Was Not Associated with a PCR following NAC. Neither good pathological responders nor those whose tumours had a pCR with NAC had a significant association with pre-NAC CD1a ${ }^{+}$TIDCs or $\mathrm{CD}^{2} 6 \mathrm{~b}^{+}$TINs. The infiltration was assessed both intratumourally and peritumourally (stroma) (Table 5). Figures 3(a) and 3(b) illustrate $\mathrm{CD}^{+}{ }^{+}$TIDCs and Figures 3(c) and 3(d) CD66 ${ }^{+}$TINs in the tumour specimens examined. There was, however, a significant reduction in the level of intratumoural infiltration, but not peritumoural, by $\mathrm{CD}^{+} \mathrm{a}^{+}$TIDCs with NAC $(p=0.001)$. 


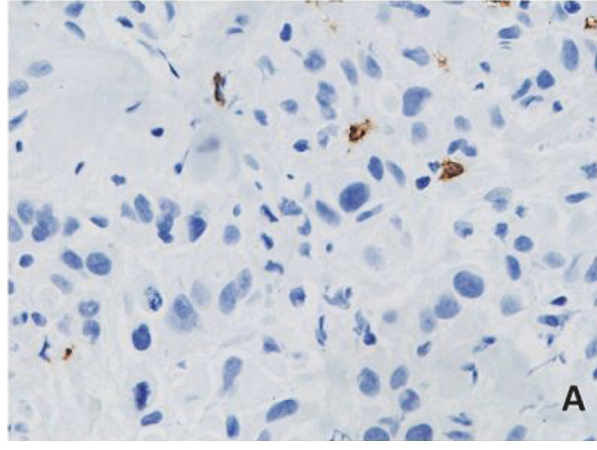

(a)

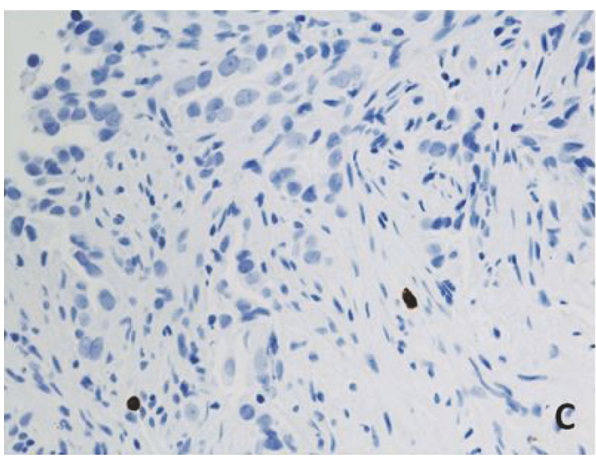

(c)

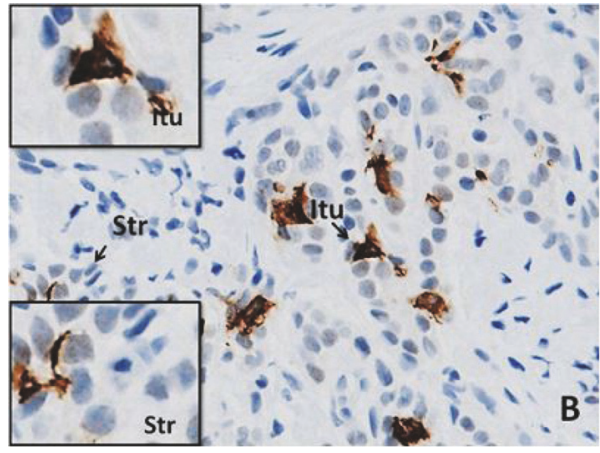

(b)

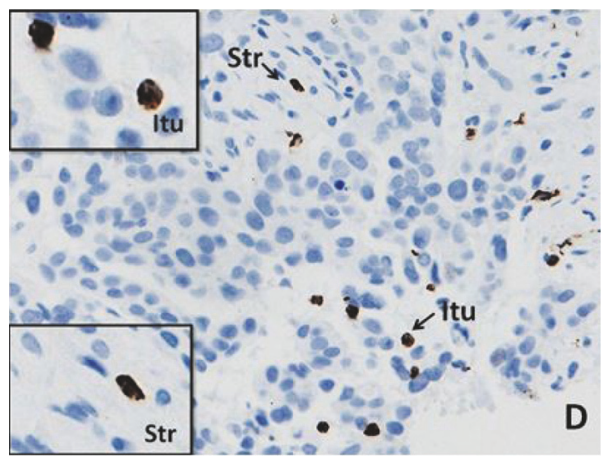

(d)

Figure 3: $\mathrm{CD}_{\mathrm{a}}{ }^{+} \mathrm{DCs}(\mathrm{a}, \mathrm{b})$ and $\mathrm{CD}_{6} \mathrm{~b}^{+}$neutrophils $(\mathrm{c}, \mathrm{d})$ in the sections of LLABCs, using IHC staining, at 400x magnification. Briefly, heat-mediated antigen retrieval was performed using citrate buffer, $\mathrm{pH} 6$ (20 mins). The sections were then incubated with MAbs to CD1a (Dako, M3571) at a 1:200 dilution for $15 \mathrm{mins}$ at RT, MAbs to CD66b (LSBio, LS-B7134) at a concentration of $10 \mu \mathrm{g} / \mathrm{ml}$ for $30 \mathrm{mins}$ at RT. Polymeric HRP-linker antibody conjugate was used as secondary antibody. DAB chromogen was used to visualize the staining. The sections were counterstained with haematoxylin. (a, c) Low level of $\mathrm{CD}^{2} \mathrm{a}^{+} \mathrm{DC}$ and $\mathrm{CD}_{6} 6 \mathrm{~b}^{+}$neutrophil infiltration; (b, d) high level of $\mathrm{CD}^{+} \mathrm{a}^{+} \mathrm{DC}$ and $\mathrm{CD}_{66} \mathrm{~b}^{+}$neutrophil infiltration. The total number of brown membrane-stained cells, regardless of intensity, in contact with tumour cells or within tumour cell nests (Itu: intratumoural) and in the interstitial stroma (Str: stromal/peritumoural) in 5 HPFs was counted.

TABLE 6: Alteration of tumour-infiltrating $\mathrm{CD} \mathrm{a}^{+}$dendritic cells and $\mathrm{CD} 6 \mathrm{~b}^{+}$neutrophils in breast tumours in women with LLABCs undergoing NAC.

\begin{tabular}{|c|c|c|c|c|}
\hline Groups & & Pre-NAC median (range) $)^{(3)}$ & Post-NAC median (range) ${ }^{(3)}$ & $p$ value $^{(4)}$ (pre- versus post-NAC) \\
\hline \multirow{2}{*}{$\mathrm{CD} \mathrm{a}^{+}$} & Intratumoural infiltration $(n=16)$ & $3.5(0-104)$ & $0(0-2)$ & $0.001^{*}$ \\
\hline & Peritumoural infiltration $(n=16)$ & $1.5(0-16)$ & $1(0-7)$ & 0.184 \\
\hline \multirow{2}{*}{$\mathrm{CD} 6 \mathrm{~b}^{+}$} & Intratumoural infiltration $(n=16)$ & $1(0-53)$ & $4.5(0-50)$ & 0.125 \\
\hline & Peritumoural infiltration $(n=16)$ & $1.5(0-71)$ & $2.5(0-82)$ & 0.470 \\
\hline
\end{tabular}

LLABCs: large and locally advanced breast cancers; NAC: neoadjuvant chemotherapy; ${ }^{(3)}$ cell count in $400 \mathrm{x}$ HPF; ${ }^{(4)}$ Wilcoxon signed-rank test; ${ }^{*}$ statistically significant.

There was, on the other hand, no intra- or peritumoural alteration in the level of $\mathrm{CD}_{6} \mathrm{~b}^{+}$TINs (Table 6).

3.5. No Significant Difference in the Levels of Macrophages $\left(\mathrm{CD}^{+} 8^{+}\right.$and $\left.C D 163^{+}\right)$, Neutrophils, and DCs in ALNs (Metastatic versus Nonmetastatic) in Women with LLABCs Undergoing NAC. There was no significant difference in the level of macrophages $\left(\mathrm{CD}^{+} 8^{+}\right.$and $\left.\mathrm{CD} 163^{+}\right)$in tumourdraining ALNs, comparing metastatic (tumour-free areas) with nonmetastatic, in women with LLABCs undergoing
NAC (Table 7). Similarly, there was no significant difference in the levels of $\mathrm{CD} \mathrm{a}^{+}$DCs or $\mathrm{CD} 6 \mathrm{~b}^{+}$neutrophils (Table 7).

The presence of $\mathrm{CD} 66 \mathrm{~b}^{+}$neutrophils and $\mathrm{CD1a}{ }^{+} \mathrm{DCs}$ in ALNs in tumour-free paracortical areas of ALNs is illustrated in Figures 4(c) and 4(d) and Figures 4(a) and 4(b), respectively.

3.6. Expression of VEGF and IDO in Women with LLABCs Undergoing NAC: CPR Significantly Associated with High Levels of VEGF in Pre-NAC Breast Cancers. High levels of 
TABLE 7: Analyses of immune cell subsets in ALNs in women with LLABCs undergoing NAC.

\begin{tabular}{|c|c|c|c|}
\hline Immune cell subsets & Groups & ALN median (range) ${ }^{(4)}$ & $p$ value $^{(5)}$ \\
\hline \multirow{2}{*}{$\mathrm{CD} 68^{+}$macrophages $(n=16)$} & Nonmetastatic ALNs $(n=9)$ & $25.0(14.8-34.0)$ & \multirow{2}{*}{0.918} \\
\hline & Metastatic ALNs $(n=7)$ & $29.0(13.8-33.0)$ & \\
\hline \multirow{2}{*}{$\mathrm{CD} 163^{+}$macrophages $(n=33)$} & Nonmetastatic ALNs $(n=9)$ & $21.0(16.0-29.0)$ & \multirow{2}{*}{1.000} \\
\hline & Metastatic ALNs $(n=24)$ & $23.0(10.0-33.0)$ & \\
\hline \multirow{2}{*}{$\mathrm{CD} \mathrm{a}^{+} \mathrm{DCs}(n=16)$} & Nonmetastatic ALNs $(n=9)$ & $12.8(0.8-62.0)$ & \multirow{2}{*}{0.536} \\
\hline & Metastatic ALNs $(n=7)$ & $23.8(6.6-67.0)$ & \\
\hline \multirow{2}{*}{$\mathrm{CD} 6 \mathrm{~b}^{+}$PMNs $(n=16)$} & Nonmetastatic ALNs $(n=9)$ & $5.2(0.6-94.0)$ & \multirow{2}{*}{0.837} \\
\hline & Metastatic ALNs $(n=7)$ & $8.4(1.0-163.0)$ & \\
\hline
\end{tabular}

ALNs: axillary lymph nodes; LLABCs: large and locally advanced breast cancers; NAC: neoadjuvant chemotherapy; ${ }^{(4)}$ average percentage of positively stained cells out of all the lymphoid cells in the ALN sections examined for $\mathrm{CD}^{+} 8^{+}$and $\mathrm{CD} 163^{+}$macrophages, average cell count of positively stained cells per $400 \mathrm{x}$ high-power field in the ALN sections examined for $\mathrm{CDla}^{+} \mathrm{DCs}$ and $\mathrm{CD}_{66 \mathrm{~b}^{+}}$PMNs; ${ }^{(5)}$ Mann-Whitney $U$ test; DCs: dendritic cells; PMNs: polymorphonuclear leukocytes.

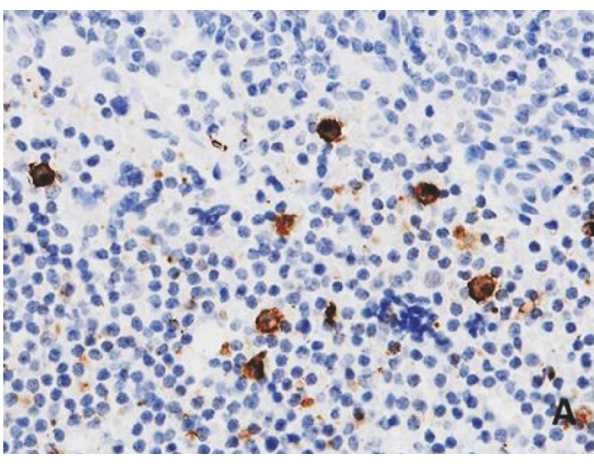

(a)

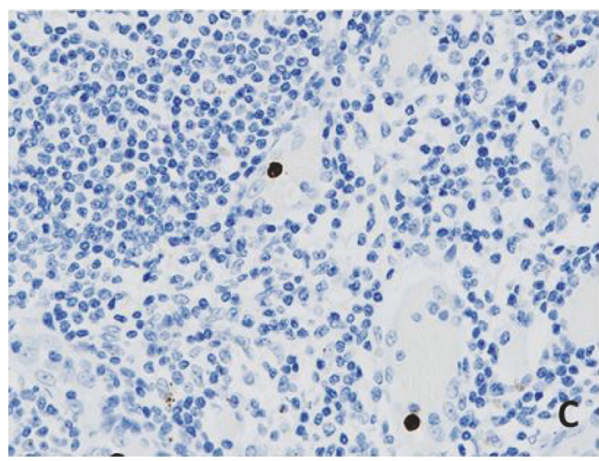

(c)

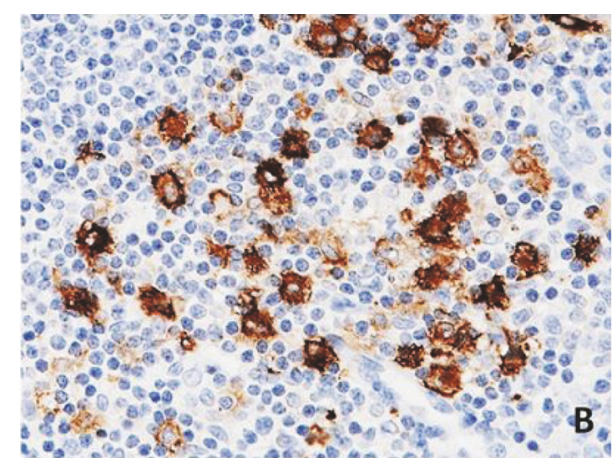

(b)

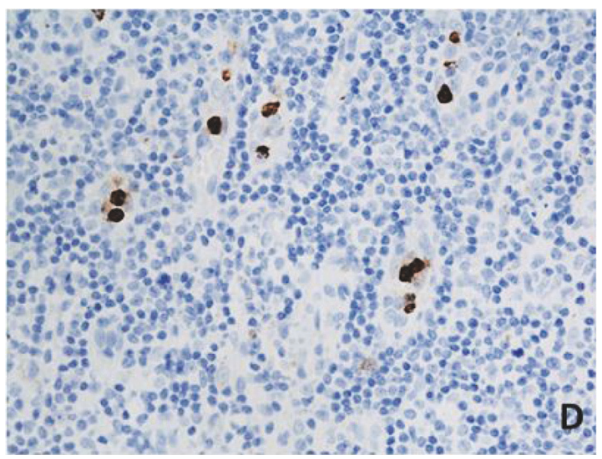

(d)

FIGURE 4: $\mathrm{CD}^{+} \mathrm{a}^{+}$DCs $(\mathrm{a}, \mathrm{b})$ and $\mathrm{CD}_{6} \mathrm{~b}^{+}$neutrophils $(\mathrm{c}, \mathrm{d})$ in the sections of axillary lymph nodes (ALNs), using IHC staining, at 400x magnification. Briefly, heat-mediated antigen retrieval was performed using citrate buffer, $\mathrm{pH} 6$ (20 mins). The sections were then incubated with MAbs to CD1a (Dako, M3571) at a 1:200 dilution for 15 mins at RT, MAbs to CD66b (LSBio, LS-B7134) at a concentration of $10 \mu \mathrm{g} / \mathrm{ml}$ for 30 mins at RT. Polymeric HRP-linker antibody conjugate was used as secondary antibody. DAB chromogen was used to visualize the staining. The sections were counterstained with haematoxylin. $(\mathrm{a}, \mathrm{c})$ Low number of $\mathrm{CD} 1 \mathrm{a}^{+} \mathrm{DCs}$ and $\mathrm{CD} 66 \mathrm{~b}^{+}$ neutrophils; (b, d) high number of $\mathrm{CD} 1 \mathrm{a}^{+} \mathrm{DCs}$ and $\mathrm{CD} 6 \mathrm{~b}^{+}$neutrophils. The average number of cell counts per HPF in tumour-free paracortical areas of ALNs with the greatest accumulation of the positive brown membrane-stained cells was quantified.

expression of VEGF in primary breast cancers were significantly associated with a pCR $(p=0.018)$ following NAC. There was no association, however, with the expression of IDO (Table 8). In addition, there was no alteration of IDO and VEGF in the primary breast cancers following NAC (Table 9).
Figure 5 illustrates the expression of VEGF (Figures 5(a) and 5(b)) and IDO (Figures 5(c) and 5(d)), respectively, in primary breast cancers.

There was no difference in the expression of IDO and VEGF in ALNs, whether metastatic (tumour-free paracortical area) or nonmetastatic (data not shown). 


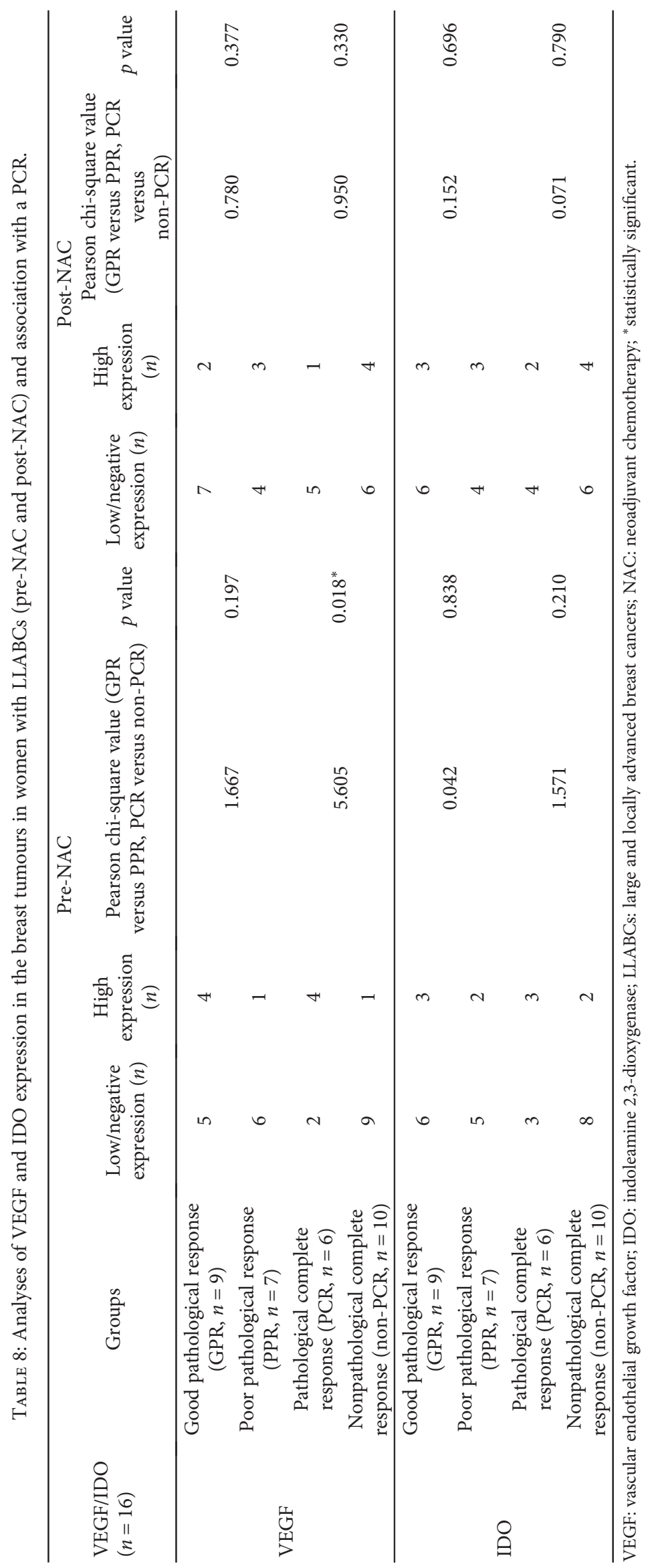


TABLE 9: No alteration of expression of IDO and VEGF in the breast tumours in women with LLABCs undergoing NAC.

\begin{tabular}{|c|c|c|c|c|c|}
\hline \multirow{2}{*}{ VEGF/IDO $(n=16)$} & & \multirow{2}{*}{ Groups } & \multicolumn{2}{|c|}{ Post-NAC } & \multirow{2}{*}{$p$ value $^{(5)}$} \\
\hline & & & Low/negative expression $(n)$ & High expression $(n)$ & \\
\hline \multirow{2}{*}{ VEGF } & \multirow{2}{*}{ Pre-NAC } & Low/negative expression $(n)$ & 8 & 3 & \multirow{2}{*}{1.000} \\
\hline & & High expression $(n)$ & 3 & 2 & \\
\hline \multirow{2}{*}{ IDO } & \multirow{2}{*}{ Pre-NAC } & Low/negative expression $(n)$ & 8 & 3 & \multirow{2}{*}{1.000} \\
\hline & & High expression $(n)$ & 2 & 3 & \\
\hline
\end{tabular}

IDO: indoleamine 2,3-dioxygenase; VEGF: vascular endothelial growth factor; LLABCs: large and locally advanced breast cancers; NAC: neoadjuvant chemotherapy; ${ }^{(5)}$ related sample McNemar Test.

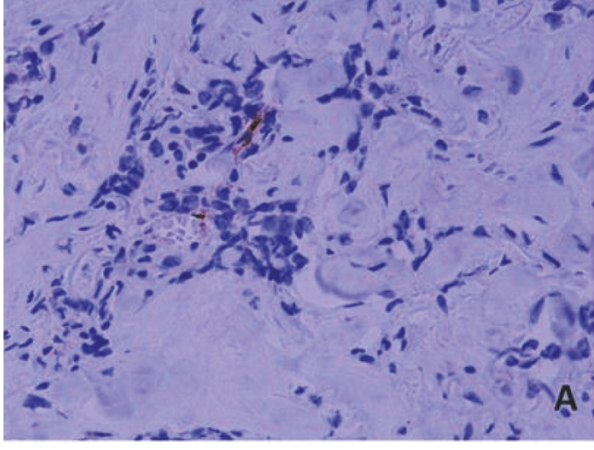

(a)

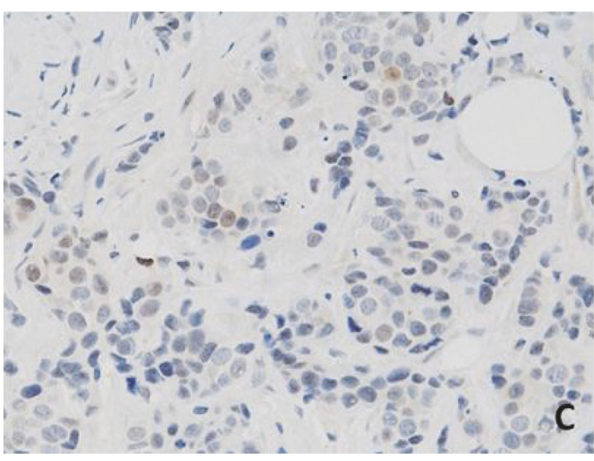

(c)

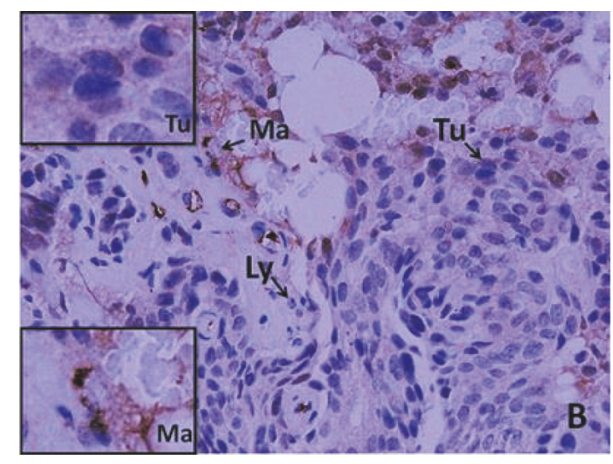

(b)

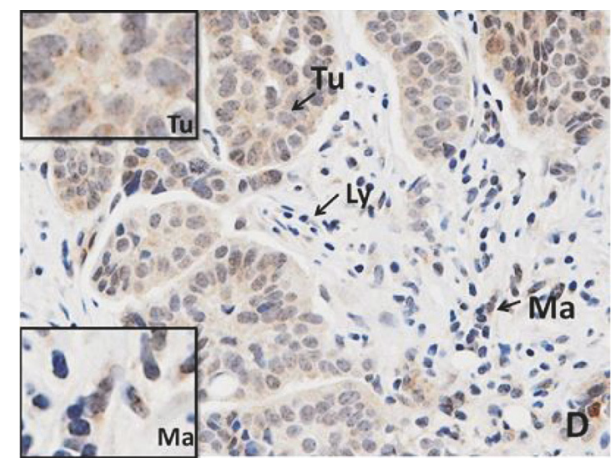

(d)

FIgURE 5: VEGF ( $a, b)$ and IDO (c, d) expression in the sections of LLABCs, using IHC staining, at 400x magnification. Briefly, heat-mediated antigen retrieval was performed using citrate buffer, $\mathrm{pH} 6$ (20 mins). The sections were then incubated with MAbs to VEGF (Dako, M7273) at a 1:50 dilution for 30 mins at RT, MAbs to IDO (Abcam, ab55305) at a concentration of $0.75 \mu \mathrm{g} / \mathrm{ml}$ for 15 mins at RT. Polymeric HRP-linker antibody conjugate was used as secondary antibody. DAB chromogen was used to visualize the staining. The sections were counterstained with haematoxylin. ( $\mathrm{a}, \mathrm{c}$ ) Low level of expression; (b, d) high level of expression. The $\mathrm{H}$ score (\% of positive cells (brown membrane/ cytoplasmic-stained tumour and immune cells) $\times$ intensity of staining (1 to 3)) was used to assess the level of expression; low was $\leq 100$ and high was $>100$. Scoring performed on a whole tissue section (7-10 HPFs); Tu: tumour, Ma: macrophage, and Ly: lymphocyte.

Figure 6 illustrates the expression of VEGF (Figures 6(a) and 6(b)) and IDO (Figures 6(c) and 6(d)), respectively, in ALNs.

\subsection{Significant Association between ER Status and Tumour} Grade with $C D 163^{+}$TIMs and PCR. High levels of $\mathrm{CD}_{163}{ }^{+}$TIMs were significantly associated with ER status $(p=0.046)$ and tumour grade $(p=0.004)$. In addition, both parameters were significantly associated with tumour pCRs following NAC ( $p=0.049, p=0.010$, resp.) (Table 10). Thus, ER-ve, high grade tumours were more likely to be infiltrated by TIMs and show a pCR with NAC. There was also a significant inverse association between pCR and recurrent disease (4-year follow-up) in the small group of patients $(n=33)$ studied $(p=0.001)$ (Table 10$)$.

3.8. High Circulating Levels of PMN Neutrophils (Pre-NAC): Significant PCR in Metastatic ALNs. High levels of circulating PMN neutrophils pre-NAC in women with LLABCs $(n=108)$ were associated with a significant pCR in metastatic ALNs following 8 cycles of NAC. There were no comparable changes in the primary breast cancers, nor any significant associations with nodal status, DFS and OS (Table 11). There was also no significant correlation between blood 


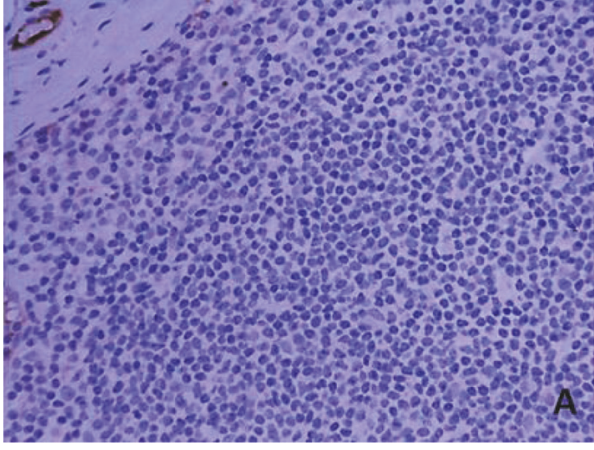

(a)

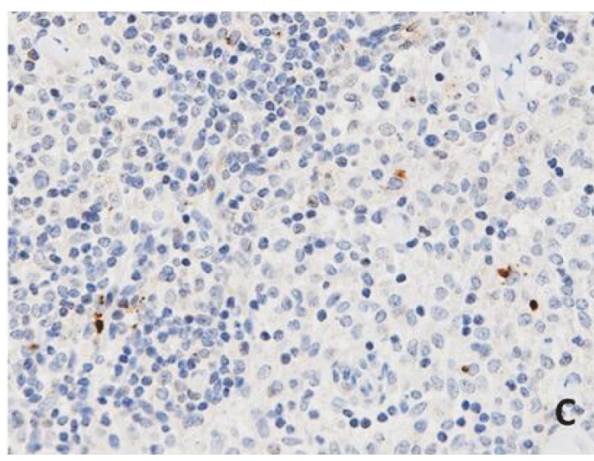

(c)

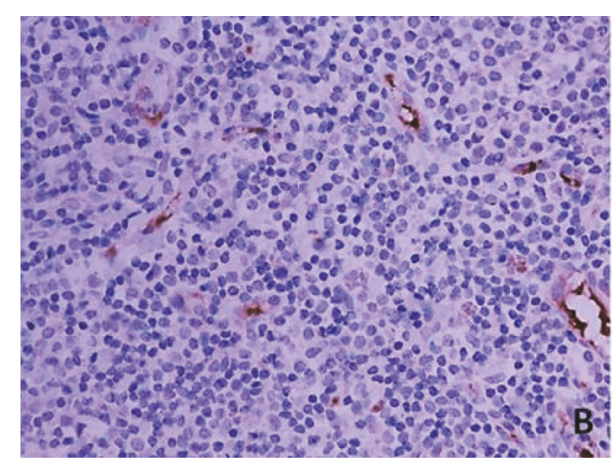

(b)

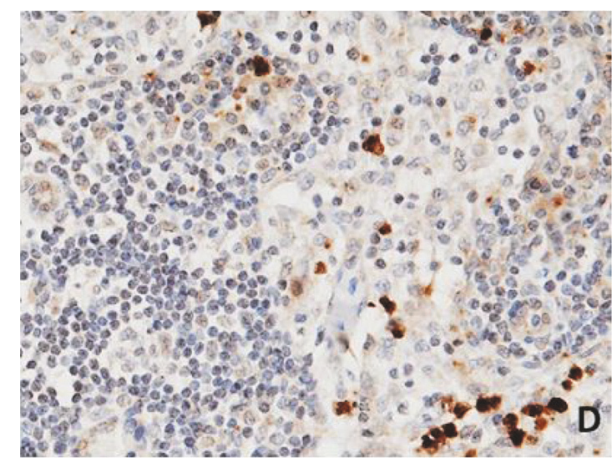

(d)

FIGURE 6: VEGF (a, b) and IDO (c, d) expression in the sections of axillary lymph nodes (ALNs), using IHC staining at 400x magnification. Briefly, heat-mediated antigen retrieval was performed using citrate buffer, $\mathrm{pH} 6$ (20 mins). The sections were then incubated with MAbs to VEGF (Dako, M7273) at a 1:50 dilution for $30 \mathrm{mins}$ at RT, MAbs to IDO (Abcam, ab55305) at a concentration of $0.75 \mu \mathrm{g} / \mathrm{ml}$ for $15 \mathrm{mins}$ at RT. Polymeric HRP-linker antibody conjugate was used as secondary antibody. DAB chromogen was used to visualize the staining. The sections were counterstained with haematoxylin. ( $a, c)$ Low level of expression; (b, d) high level of expression. The $\mathrm{H}$ score (\% of positive cells (brown membrane/cytoplasmic-stained cells) $\times$ intensity of staining ( 1 to 3$)$ ) was used to assess the level of expression; low was $\leq 100$ and high was $>100$. Scoring performed on nonmetastatic areas of a whole ALN section (7-10 HPFs).

and tumour-infiltrating $\mathrm{CD} 6 \mathrm{~b}^{+}$neutrophils in patients following 8 cycles of NAC (data not shown). There was a significant reduction in the circulating levels of PMN neutrophils $(p=0.001)$ after NAC (Table 12). All patients were given granulocyte colony-stimulating factor (G-CSF) following randomisation.

3.9. Circulating Levels of DCs, mDC1s and pDCs, and Expression of Costimulatory and Lymph Node Homing Molecules in Women with LLABCs: Reduction in Blood Levels and Expression of Costimulatory Molecules. The \% of DCs in the blood of women with LLABCs $(n=30)$ was significantly reduced $(1.26 \pm 0.20 \%)$ compared with healthy, age-matched female donors (HFDs $(n=9): 1.70$ $\pm 0.30)(p=0.034)$. The $\%$ of $\mathrm{mDC} 1 \mathrm{~s}^{\text {high }}$ was also significantly reduced compared with HFDs $(0.10 \pm 0.04 \%$ versus $0.15 \pm 0.05 \%, p=0.045)$, as was the $\% \mathrm{pDCs}^{\text {high }}(0.03$ $\pm 0.02 \%$ versus $0.06 \pm 0.02 \%, p=0.041$ ) (Table 13 ).

The expression of the costimulatory molecule HLA$\mathrm{DR}$ was significantly reduced in both the blood $\mathrm{mDC1}^{+}$and $\mathrm{pDC}^{+}$subsets, compared with HFDs $(47.30 \pm 8.00 \%$ versus $65.00 \pm 3.10 \% \quad(p=0.045), \quad 48.12 \pm 9.50 \%$ versus 65.52 $\pm 5.00 \%(p=0.002)$, resp.) (Table 13$)$.

The expression of CD40 and CD83 was also depressed in mDC1s ${ }^{\text {high }}$, compared with HFDs $(35.01 \pm 8.00 \%$ versus
$44.87 \pm 6.50 \%(p=0.011), 3.18 \pm 0.40 \%$ versus $4.04 \pm 0.30 \%$ $(p=0.047)$, resp.). The expression of CD80, CD86, and LNHR CD197 on the mDC1s ${ }^{\text {high }}$ were unaltered (Table 13). The levels of expression of these receptors on pDCs were inconsistent and difficult to document due to the small numbers of these cells in the blood, and apart from HLADR expression, are not shown.

3.10. Effect of NAC on the Circulating Levels of DCs in Women with LLABCs: Good Pathological Responders Have Significantly Increased Blood Levels following NAC. Before NAC, the \% baseline levels of DCs in women who subsequently had a good pathological response with NAC $(n=9)$ were comparable with those that had a poor pathological response $(n=7)(1.64 \pm 0.25$ versus $1.29 \pm 0.25)$ (Table 14). The \% levels of blood DCs following 8 cycles of NAC and in those who had a good pathological response (pCR or $\geq 90 \%$ reduction in tumour mass) with NAC, however, were increased. This was even significantly higher than the levels documented in HFDs $(3.24 \pm 1.62$ versus $1.70 \pm 0.30, p=0.024$ ) (Table 14). There was no alteration in the post-NAC levels of circulating DCs in those patients whose tumours showed a poor pathological response (no response or $<90 \%$ reduction in tumour mass) (Table 14). 
TABLE 10: Clinical and pathological parameters of patients $(n=33)$ studied and the Association of pre-NAC tumour-infiltrating CD163 ${ }^{+}$ macrophages (TIMs) and pathological complete response (PCR).

\begin{tabular}{|c|c|c|c|c|c|c|c|c|}
\hline \multirow[b]{2}{*}{ Groups } & \multicolumn{4}{|c|}{ TIMs } & \multicolumn{4}{|c|}{ PCR } \\
\hline & $\begin{array}{l}\text { Low infiltration } \\
(n)\end{array}$ & $\begin{array}{l}\text { High infiltration } \\
(n)\end{array}$ & $\begin{array}{c}\text { Pearson chi-square } \\
\text { value }\end{array}$ & $p$ value & $\begin{array}{l}\text { Non-PCR } \\
(n)\end{array}$ & $\begin{array}{l}\text { PCR } \\
(n)\end{array}$ & $\begin{array}{l}\text { Pearson chi-square } \\
\text { value }\end{array}$ & $p$ value \\
\hline \multicolumn{9}{|l|}{ Age (years) } \\
\hline$<50$ & 6 & 8 & \multirow{2}{*}{0.002} & \multirow{2}{*}{0.966} & 8 & 6 & \multirow{2}{*}{0.308} & \multirow{2}{*}{0.579} \\
\hline$\geq 50$ & 8 & 11 & & & 9 & 10 & & \\
\hline \multicolumn{9}{|l|}{ BMI $\left(\mathrm{kg} / \mathrm{m}^{2}\right)$} \\
\hline$\leq 30$ & 10 & 10 & \multirow{2}{*}{1.193} & \multirow{2}{*}{0.275} & 11 & 9 & \multirow{2}{*}{0.247} & \multirow{2}{*}{0.619} \\
\hline$>30$ & 4 & 9 & & & 6 & 7 & & \\
\hline \multicolumn{9}{|l|}{$\begin{array}{l}\text { Menopausal } \\
\text { status }\end{array}$} \\
\hline Pre & 5 & 11 & \multirow{2}{*}{1.588} & \multirow{2}{*}{0.208} & 8 & 8 & \multirow{2}{*}{0.029} & \multirow{2}{*}{0.866} \\
\hline Post & 9 & 8 & & & 9 & 8 & & \\
\hline \multicolumn{9}{|l|}{ Tumour size } \\
\hline$<40 \mathrm{~mm}$ & 8 & 10 & \multirow{2}{*}{0.066} & \multirow{2}{*}{0.797} & 9 & 9 & \multirow{2}{*}{0.036} & \multirow{2}{*}{0.849} \\
\hline$\geq 40 \mathrm{~mm}$ & 6 & 9 & & & 8 & 7 & & \\
\hline \multicolumn{9}{|l|}{ Nodal status } \\
\hline Negative & 5 & 5 & \multirow{2}{*}{0.337} & \multirow{2}{*}{0.561} & 5 & 5 & \multirow{2}{*}{0.013} & \\
\hline Positive & 9 & 14 & & & 12 & 11 & & 0.909 \\
\hline Tumour grade & & & & & & & & \\
\hline 1 (low) & 1 & 1 & & & 2 & 0 & & \\
\hline 2 (moderate) & 10 & 3 & 11.270 & $0.004^{*}$ & 10 & 3 & 9.303 & $0.010^{*}$ \\
\hline 3 (high) & 3 & 15 & & & 5 & 13 & & \\
\hline $\begin{array}{l}\text { Oestrogen } \\
\text { receptor }\end{array}$ & & & & & & & & \\
\hline Negative & 2 & 9 & 3070 & $0.046^{*}$ & 3 & 8 & 3882 & $0.049 *$ \\
\hline Positive & 12 & 10 & 5.970 & & 14 & 8 & 3.002 & \\
\hline HER-2 receptor & & & & & & & & \\
\hline Negative & 10 & 13 & 0035 & 0853 & 13 & 10 & 0762 & 0383 \\
\hline Positive & 4 & 6 & 0.055 & 0.055 & 4 & 6 & 0.702 & 0.505 \\
\hline NAC regimen & & & & & & & & \\
\hline AC-TX & 6 & 10 & 0308 & 0570 & 6 & 10 & 2443 & 0118 \\
\hline AC-T & 8 & 9 & 0.500 & 0.379 & 11 & 6 & 2.443 & 0.110 \\
\hline $\begin{array}{l}\text { Recurrent } \\
\text { disease }^{(4)}\end{array}$ & & & & & & & & \\
\hline No & 8 & 14 & 0.992 & 0.319 & 7 & 15 & 10.252 & $0.001^{*}$ \\
\hline Yes & 6 & 5 & 0.992 & 0.319 & 10 & 1 & 10.252 & 0.001 \\
\hline Death $^{(4)}$ & & & & & & & & \\
\hline No & 11 & 16 & 0172 & & 12 & 15 & & \\
\hline Yes & 3 & 3 & 0.172 & 0.678 & 5 & 1 & 2.972 & 0.085 \\
\hline
\end{tabular}

NAC: neoadjuvant chemotherapy; BMI: body mass index ( $\leq 30$ : nonobese, $>30$ : obese); AC-TX: doxorubicin, cyclophosphamide, taxotere, and xeloda ${ }^{\circledR}$ (capecitabine), respectively; ${ }^{(4)} 4$-year follow-up; ${ }^{*}$ statistically significant.

\subsection{Effect of NAC on the Circulating Levels and Expression of} Costimulatory Molecules on mDC1s and pDCs: Blood Levels and Expression Lower in PPRs. After 8 cycles of NAC, those women whose breast cancers showed a PPR had significantly lower levels of blood mDC1s ${ }^{\text {high }}(p=0.048)$ and $\mathrm{pDCs}^{\text {high }}(p=0.017)$ and expression of HLA-DR ( $p=0.001, p=0.023$, resp.), when compared with the blood levels of HFDs. Women whose tumours showed a GPR had no alterations in circulating levels (Table 15).
After 8 cycles of NAC, women whose breast cancers showed a PPR also had significantly lower levels of expression of $\operatorname{mDC1} \mathrm{CD} 40(p=0.001)$ and CD86 ( $p=0.001)$, compared with HFDs. These findings were not seen in women whose tumours had GPRs (Table 16).

Comparison of blood levels of $\mathrm{mDC} 1$ expression of costimulatory and LNH molecules between GPRs and PPRs showed a significant reduction in CD40, CD86, and CD197 expression on circulating $\mathrm{mDC} 1 \mathrm{~s}(p=0.005, p=0.004$, and 
$p=0.003$, resp.) following NAC in patients whose tumours had a PPR (Table 16).

These findings demonstrate the significant association between the reduced \% (mDC1s and $\mathrm{pDCs})$ and expression of HLA-DR (mDC1s and pDCs), CD40, and CD86 (mDC1s) and failure to achieve a GPR with NAC. Thus, women whose breast cancers failed to undergo a GPR with NAC showed significantly reduced, inactive, and immature DC subsets in the circulation.

\section{Discussion}

In the current study reported, the CD163 ${ }^{+}$TIMs (M2 macrophage phenotype) in both the primary breast cancer and metastatic ALNs were significantly associated with pCRs in malignant tissue following NAC. TIMs are derived from circulating monocytes and primitive bone marrow progenitors [58]. They are recruited into the tumour milieu by various chemokines (e.g., CCL2) and factors released by necrotic cells, in response to hypoxia and the cancer-associated fibroblasts [59]. Once embedded in the tumour microenvironment, the monocytes mature into the predominant M2 expressing CD163 (haemoglobin scavenger receptor) macrophages and are activated by Th 2 cytokines interleukin- 4 (IL-4) and IL-10 $[19,60,61]$. The M2 phenotype favours tumour growth and metastatic spread through the promotion of angiogenesis, production of metalloproteinases, and inhibition of cytotoxic T lymphocytes (CTLs) by TGF- $\beta$ and IL-10. TIMs also secrete arginase 1 in the tumour microenvironment, reducing L-arginine in situ and inhibiting CTL production and function [19, 60, 62-64]. Bingle et al., in a meta-analysis of various solid cancers, including breast cancer, showed that high levels of M2 TIMs were associated with a poor DFS and OS and this is supported by other, more recent publications [22, 65].

A pCR following NAC in breast cancer has been shown in some studies to be a surrogate marker for a good prognosis and survival $[46,66]$. Cortazar et al. described a correlation between favourable outcome and pCR in breast cancer [67]. Our findings suggest that high levels of $\mathrm{CD} 163^{+}$TIMs in LLABCs are a predictor for a good pathological response and pCR but not necessarily for DFS and OS. In our study, there was a significant association between TIMs and tumour ER status and grade and between PCR and tumour ER status and grade. Highly proliferative, triple-negative breast cancers are significantly associated with high rates of $\mathrm{pCR}$ but have a poor DFS and OS $[9,46,68]$. Esserman et al. showed by studying breast cancer subsets that a $\mathrm{PCR}$ was a better predictor for a DFS [69]. A recent analysis revealed that although patients in whom there was a PCR in the tumour had a more favourable outcome, this did not always result in an improvement in OS [70].

M1 TIMs are activated by interferon- $\gamma($ IFN- $\gamma)$ and bacterial products, produce proinflammatory cytokines, express IL-12, enhance adaptive immunity, and induce lysis of tumour cells [19-21]. In contrast to the presence of the M2 $\mathrm{CD}_{163^{+}}$TIMs, the M1CD68 ${ }^{+}$TIMs had no demonstrable association with a pCR. Heys et al. studied TIM subsets in breast cancer, using CD68 (general macrophage marker) expression of suppression of cytokine signalling (SOCS) 1 and SOCS 3 [24]. SOCS 1 (M2 phenotype) inhibits the proinflammatory signalling pathways downstream of IFN $-\gamma$ and Toll-like receptor 4, whilst SOCS 3 (M1 phenotype) inhibits signal transduction and activation of transcription 3 (STAT 3) signalling. High levels of SOCS $3^{+}$TIMs in LLABCs were associated with a pCR with NAC. There was, however, no association between SOCS $1^{+}$TIMs and pathological response to NAC [24]. Thus, M1 and M2 TIM subsets, characterised by the expression of specific cellular functional markers, were associated with significant rates of $\mathrm{pCR}$ following NAC.

In sentinel lymph nodes (SLNs), Mansfield et al. found that the presence of sinusoidal $\mathrm{CD}_{163^{+}} \mathrm{M} 2$ macrophages was associated with a favourable nodal status in patients with breast cancer. They did not investigate TIMs in metastatic SLNs [54]. In our study, there was a significant association between the level of $\mathrm{CD}_{163}{ }^{+}$TIMs in metastases in tumour-draining ALNs, prior to NAC and the subsequent pCR following 8 cycles of NAC. Our study, on the other hand, found no significant difference in the level of $\mathrm{CD} 163^{+}$ macrophages in metastatic (tumour-free areas) versus nonmetastatic medullary areas in ALNs. The significant association between $\mathrm{CD}_{163^{+}}$TIMs in primary breast cancers and metastatic ALNs and pCRs with NAC has not been previously reported.

In patients with cancer, blood neutrophils tend to be immature and produce low levels of free radicals [26]. Increased levels of blood neutrophils have been documented in various tumours, including breast cancer, and shown to be associated with poor clinical outcomes [26]. Their association with pathological responses with NAC, however, has not been described. We did not demonstrate any association between blood neutrophils and poor clinical outcome, nor with a pCR in the primary tumour, in our cohort of 108 patients. We did, however, document a significant association between circulating levels of neutrophils, prior to NAC, and subsequent pCR in metastatic ALNs, a finding not previously described.

There were significantly reduced blood levels of PMN neutrophils following NAC, albeit all patients were given granulocyte colony-stimulating factor following randomisation.

Tumour entry of PMN neutrophils is induced by chemotactic molecules secreted by intratumoural TIMs and cancer cells $[27,28]$. High levels of CD66b ${ }^{+}$TINs have been found previously to be significantly associated with poor DFS and OS in a variety of nonbreast solid cancers [30-32]. In our study of women with LLABCs, CD66b ${ }^{+}$TINs were not significantly associated with pathological responses to NAC. They were also resistant to NAC. The TINs were present in small numbers in the tumour microenvironment, and only a small cohort $(n=16)$ of patients was studied. A larger series is required to confirm these findings. There are, however, no published articles documenting their relevance in women with LLABCs undergoing NAC.

In tumour-draining metastatic ALNs, there was also no significant association between the level of infiltration by $\mathrm{CD} 6 \mathrm{~b}^{+}$TINs and pCR with NAC. Moreover, there was no difference in the level of infiltration by $\mathrm{CD} 6 \mathrm{~b}^{+}$neutrophils 
TABLE 11: Analyses of blood PMN neutrophils in women with LLABC and specific clinical and pathological parameters.

\begin{tabular}{|c|c|c|c|c|c|}
\hline Groups & & $\begin{array}{l}\text { Pre-NAC } \\
\text { median } \\
(\text { range })^{(3)}\end{array}$ & $\begin{array}{c}p \text { value }^{(4)} \\
\text { (GPR versus } \mathrm{PRR}, \mathrm{PCR} \\
\text { versus non-PCR) }\end{array}$ & $\begin{array}{c}\text { Post-NAC } \\
\text { median (range) }\end{array}$ & $\begin{array}{l}p \text { value }^{(4)} \text { (GPR versus PRR, } \\
\text { PCR versus non-PCR) }\end{array}$ \\
\hline \multirow{12}{*}{$\begin{array}{l}\text { Blood } \\
\text { PMNs }\end{array}$} & $\begin{array}{l}\text { Good pathological response } \\
\qquad(\mathrm{GPR}, n=52)\end{array}$ & $4.13(2.15-11.30)$ & \multirow[b]{2}{*}{0.796} & $3.05(1.40-6.75)$ & \multirow[b]{2}{*}{0.134} \\
\hline & $\begin{array}{l}\text { Poor pathological } \\
\text { response }(\mathrm{PPR}, n=56)\end{array}$ & $4.07(1.80-10.10)$ & & $3.47(0.03-8.73)$ & \\
\hline & $\begin{array}{l}\text { Pathological complete } \\
\text { response (PCR, } n=29)\end{array}$ & $4.50(2.15-11.30)$ & \multirow[b]{2}{*}{0.381} & $3.10(1.40-6.75)$ & \multirow[b]{2}{*}{0.755} \\
\hline & $\begin{array}{l}\text { Nonpathological } \\
\text { complete response } \\
(\text { non-PCR, } n=79)\end{array}$ & $3.94(1.80-10.10)$ & & $3.26(0.03-8.73)$ & \\
\hline & $\begin{array}{l}\text { Nodal metastasis } \\
\quad(n=56)\end{array}$ & $3.94(1.80-10.10)$ & \multirow{2}{*}{0.634} & $3.11(0.03-8.26)$ & \multirow[b]{2}{*}{0.337} \\
\hline & $\begin{array}{l}\text { No nodal metastasis } \\
\qquad(n=52)\end{array}$ & $4.16(2.15-11.30)$ & & $3.36(1.54-8.73)$ & \\
\hline & $\begin{array}{l}\text { Nodal pCR } \\
\quad(n=16)\end{array}$ & $5.43(2.84-10.10)$ & \multirow{2}{*}{$0.002^{*}$} & $3.20(1.40-8.26)$ & \multirow{2}{*}{0.892} \\
\hline & $\begin{array}{l}\text { No nodal pCR } \\
\quad(n=40)\end{array}$ & $3.65(1.80-9.17)$ & & $3.05(0.03-6.37)$ & \\
\hline & $\begin{array}{l}\text { Recurrent disease }{ }^{(5)} \\
\qquad(n=23)\end{array}$ & $4.02(1.80-8.70)$ & \multirow[b]{2}{*}{0.612} & $3.19(0.03-5.80)$ & \multirow{2}{*}{0.878} \\
\hline & $\begin{array}{l}\text { No recurrent disease } \\
\qquad(n=85)\end{array}$ & $4.10(2.15-11.30)$ & & $3.23(1.33-8.73)$ & \\
\hline & Death $^{(5)}(n=17)$ & $3.87(2.23-6.64)$ & \multirow{2}{*}{0.276} & $3.00(0.03-5.42)$ & \multirow{2}{*}{0.360} \\
\hline & Survive $(n=91)$ & $4.11(1.80-11.30)$ & & $3.23(1.33-8.73)$ & \\
\hline
\end{tabular}

LLABC: large and locally advanced breast cancers; NAC: neoadjuvant chemotherapy; ${ }^{(3)} \times 10{ }^{9}$ cells/litre; ${ }^{(4)}$ Mann-Whitney $U$ test; ${ }^{(5)} 4$-year follow-up; *statistically significant.

TABLE 12: Alteration of blood PMN neutrophils in women with LLABCs undergoing NAC.

\begin{tabular}{|c|c|c|c|}
\hline Group & Pre-NAC median (range) ${ }^{(3)}$ & Post-NAC median (range) $)^{(3)}$ & $p$ value $^{(4)}$ (pre- versus post-NAC) \\
\hline Blood PMNs $(n=108)$ & $4.09(1.80-11.30)$ & $3.20(0.03-8.73)$ & $<0.001^{*}$ \\
\hline
\end{tabular}

in the paracortical areas of metastatic (tumour-free areas) and nonmetastatic ALNs. Such findings have not previously been documented.

In our study, we investigated tumour-infiltrating $\mathrm{CD}_{\mathrm{a}}{ }^{+}$ DCs and concurrently circulating $\mathrm{DCs}, \mathrm{mDC} 1 \mathrm{~s}^{\text {high }}$ and $\mathrm{pDCs}^{\text {high }}$. In solid cancers, evidence suggests that DCs in the tumour-microenvironment are present in small numbers, are immature, and poorly activated $[41,71,72]$. In patients with operable breast cancer, DCs in both ALNs and in the circulation have been shown to be dysfunctional [43]. In breast and ovarian cancer, moreover, TIDCs have been shown to be immunosuppressive, inhibiting the production of CTLs [38].

Although the presence of TIDCs has been documented to be associated with a better clinical outcome in a number of human solid cancers, this is not the case with CD1a ${ }^{+}$TIDCs in breast cancer [44, 73-75]. There has, however, been no previously published study regarding $\mathrm{CD}^{+}{ }^{+}$TIDCs in LLABCs and the pathological responses with NAC. Our findings showed no significant association between the levels of $\mathrm{CD} \mathrm{a}^{+}$TIDCs and pCR in either the primary tumours or metastatic ALNS. There is evidence that DCs in breast cancer (primary tumours and ALNs) are not only poorly activated and immature but may be also immunosuppressive, inhibiting the generation of CTLs and inducing $\mathrm{T}$ cell tolerance $[38,41,43]$. Tumour-induced inhibition of DC maturation and function is an important mechanism exploited by malignant cells to evade anticancer immunity $[1,76,77]$. Dumitriu et al. showed that DCs in the presence of lung carcinoma cells in vitro induced the secretion of TGF- $\beta$ and enhanced the generation of $\mathrm{CD}^{+} \mathrm{CD}^{2} 5^{+} \mathrm{FOXP}^{+}$Tregs [77]. We found that NAC significantly reduced the levels of intratumoural $\mathrm{CD}_{\mathrm{a}}{ }^{+}$DCs although it had no effect on TIMs and TINs. NAC, by significantly reducing suppressor cells (Tregs and myeloid-derived suppressor cells) within the tumour microenvironment, may have contributed to the immuneassociated tumour cell death [13, 57]. NAC, concurrently, had significant inhibitory effects on the circulating levels of DCs in the same cohort of patients.

The percentages of circulating levels of $\mathrm{DCs}, \mathrm{mDC} 1 \mathrm{~s}$ and pDCs, were significantly reduced in women with LLABCs when compared with healthy females. In addition, the 
TABLE 13: Percentage of DC subsets and expression of costimulatory and LNH molecules in the circulation of women with LLABCs.

\begin{tabular}{|c|c|c|c|}
\hline $\mathrm{mDC} 1 \mathrm{~s}$ and $\mathrm{pDCs}$ & $\begin{array}{l}\% \text { of subsets and costimulatory molecules in women } \\
\text { with LLABCs }(n=30)\end{array}$ & $\begin{array}{l}\% \text { of subsets and costimulatory molecules } \\
\text { in HFDs }(n=10)\end{array}$ & $p$ value \\
\hline${\text { Lin } 1^{-}, \text {HLA-DR }}^{+}$DCs & $1.26 \pm 0.20$ & $1.70 \pm 0.30$ & $0.034^{*}$ \\
\hline $\begin{array}{l}\mathrm{mDC1} 1^{\text {high }}\left(\mathrm{Lin1}^{-}, \text {HLA- } \mathrm{DR}^{+},\right. \\
\left.\mathrm{CD} 11 \mathrm{c}^{+} \mathrm{CD} 1 \mathrm{c}^{+}\right)\end{array}$ & $0.10 \pm 0.04$ & $0.15 \pm 0.05$ & $0.045^{*}$ \\
\hline 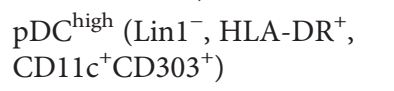 & $0.03 \pm 0.02$ & $0.06 \pm 0.02$ & $0.041^{*}$ \\
\hline mDC1 HLA-DR ${ }^{+}$ & $47.30 \pm 8.00$ & $65.00 \pm 3.10$ & $0.045^{*}$ \\
\hline pDC HLA-DR ${ }^{+}$ & $48.12 \pm 9.50$ & $65.52 \pm 5.00$ & $0.002^{*}$ \\
\hline $\mathrm{mDC} 1 \mathrm{CD} 40^{+}$ & $35.01 \pm 8.00$ & $44.87 \pm 6.50$ & $0.011^{*}$ \\
\hline $\mathrm{mDC} 1 \mathrm{CD} 80^{+}$ & $1.40 \pm 0.60$ & $1.87 \pm 0.35$ & NS \\
\hline $\mathrm{mDC} 1 \mathrm{CD}^{2} 3^{+}$ & $3.18 \pm 0.40$ & $4.04 \pm 0.30$ & $0.047^{*}$ \\
\hline $\mathrm{mDC} 1 \mathrm{CD} 86^{+}$ & $28.56 \pm 3.00$ & $34.07 \pm 8.00$ & NS \\
\hline $\mathrm{mDC} 1 \mathrm{CD} 197^{+}$ & $20.35 \pm 4.50$ & $24.68 \pm 9.00$ & NS \\
\hline
\end{tabular}

LNH: lymph node homing; LLABCs: large and locally advanced breast cancers; mDC1: myeloid dendritic cell; pDC: plasmacytoid dendritic cell; HFDs: healthy female donors; NS: nonsignificant; ${ }^{*}$ statistically significant.

expression of HLA-DR, CD40, and CD83 molecules on the surface of $\mathrm{mDC} 1 \mathrm{~s}$ were also significantly reduced, as was HLA-DR expression of pDCs. The expression of the costimulatory molecules CD80/86 was unchanged compared with healthy females. We did not carry out any functional assays to ascertain specific effector functions such as efficacy in antigen presentation and secretion of cytokines. NAC, in particular anthracyclines and taxanes, is known to disrupt tumour cells, exposing expression of calreticulin and release of tumour-associated antigens (TAAs) $[78,79]$. This drug combination was used in our NAC study [46].

There was a significant difference in the level of circulating DCs between those patients whose tumours showed a good pathological response (GPR; pCR or $\geq 90 \%$ loss of tumour cell mass) and those whose tumours had a poor pathological response (PPR; no or $<90 \%$ loss of tumour cell mass) to 8 cycles of NAC. Following NAC, the blood DC levels in the GPR group were increased and were significantly higher than the levels documented in healthy females. There was also a significantly reduced $\%$ of circulating $\mathrm{mDC} 1 \mathrm{~s}^{\text {high }}$ and $\mathrm{pDCs}^{\text {high }}$ and reduced expression of HLA-DR, CD40, and CD83 on $\mathrm{mDC} 1 \mathrm{~s}^{\text {high }}$ and HLA-DR on $\mathrm{pDCs}^{\text {high }}$ in those patients whose tumours showed a PPR to NAC. In addition, post-NAC patients whose tumours had a GPR had a significantly increased expression of HLA-DR, CD40, CD86, and the LNHR CD197. These significant associations suggest a possible and important interaction between DCs and TAA presentation to naïve $\mathrm{T}$ cells and immune-induced tumour cell death during NAC. The findings documented, to the best of our knowledge, have not been published previously.

Many chemotherapeutic drugs produce short-lived inhibitory effects on innate and adaptive immune cells. Some (anthracyclines, taxanes, cyclophosphamide, capecitabine, and gemcitabine), however, can enhance or suppress specific aspects of the immune mechanism and activate immunemediated tumour cell death, contributing to the good pathological responses documented in primary cancers and metastatic ALNs [13, 79-85], (Kaewkangsadan et al., 2016b
TABLE 14: Effect of NAC on blood DC levels in women with LLABCs.

\begin{tabular}{lc}
\hline Pathological responders & $\begin{array}{c}\text { DC baseline levels (\%) } \\
p \text { value }\end{array}$ \\
\hline GPRs + PPRs & $1.34 \pm 0.30$ \\
GPRs + PPRs versus HFDs & $\mathrm{NS}$ \\
GPRs & $1.64 \pm 0.25$ \\
GPRs versus HFD & $\mathrm{NS}$ \\
PPRs & $1.29 \pm 0.25$ \\
PPRs versus HFDs & $\mathrm{NS}$ \\
\hline Pathological responders & DC post-NAC levels (\%) \\
\hline GPRs & $p$ value \\
GPRs versus HFDs & $3.24 \pm 1.62$ \\
PPRs & $0.024^{*}$ \\
PPRs versus HFDs & $2.17 \pm 0.5$ \\
\hline
\end{tabular}

NAC: neoadjuvant chemotherapy; LLABCs: large and locally advanced breast cancers; GPRs: good pathological responders (pCR or $\geq 90 \%$ reduction of invasive disease); PPRs: poor pathological responders (no response or $<90 \%$ reduction of invasive disease); HFDs: healthy female donors; NS: nonsignificant; * statistically significant.

submitted for publication). Chemotherapy, in particular anthracyclines, induces cancer cell stress and damage with resultant release of "danger signals" and release of immunogenic TAAs, enhancing the production of and tumour infiltration by TAA-specific $\mathrm{CD}^{+}$CTLs [78, 86, 87]. Capecitabine is converted to 5-fluorouracil in the body, increasing the expression of TAAs and inducing antibodydependent cell-mediated cytotoxicity $[88,89]$. Taxanes have been shown to increase circulating levels of INF- $\gamma$, IL-2, and IL-6, as well as enhancing NK cell cytotoxicity [80, 90]. Moreover, metronomic low dose cyclophosphamide has been documented to reduce the number and activity of FOXP $^{+}$Tregs and to restore $\mathrm{T}$ effector and $\mathrm{NK}$ cell function in patients with disseminated disease [81]. 
TABLE 15: Percentage of DC subsets and expression of HLA-DR in the blood of women with LLABC undergoing NAC. Baseline (B) levels in LLABCs versus completion of chemotherapy (CC) levels in different responders.

\begin{tabular}{|c|c|c|c|c|c|}
\hline Study group comparisons & & $\mathrm{mDC} 1$ & $\begin{array}{c}\text { mDC1 } \\
\text { HLA-DR }\end{array}$ & $\mathrm{pDC}$ & $\begin{array}{c}\text { pDC } \\
\text { HLA-DR }\end{array}$ \\
\hline \multirow{4}{*}{ Good pathological responders (GPRs: $n=9$ ) } & $\mathrm{B}(\%)$ & $0.12 \pm 0.04$ & $36.07 \pm 6.00$ & $0.02 \pm 0.02$ & $50.86 \pm 10.5$ \\
\hline & CC $(\%)$ & $0.10 \pm 0.04$ & $46.33 \pm 8.00$ & $0.05 \pm 0.02$ & $58.05 \pm 12.00$ \\
\hline & $\begin{array}{c}\text { B versus CC } \\
\text { ( } p \text { value })\end{array}$ & NS & NS & NS & NS \\
\hline & $\begin{array}{l}\text { CC versus HFDs } \\
(p \text { value })\end{array}$ & NS & NS & NS & NS \\
\hline \multirow{4}{*}{ Poor pathological responders (PPRs: $n=7$ ) } & $\mathrm{B}(\%)$ & $0.08 \pm 0.03$ & $31.29 \pm 6.00$ & $0.02 \pm 0.02$ & $53.21 \pm 10.00$ \\
\hline & CC $(\%)$ & $0.05 \pm 0.03$ & $29.83 \pm 5.00$ & $0.03 \pm 0.02$ & $49.97 \pm 6.00$ \\
\hline & $\begin{array}{c}\mathrm{B} \text { versus } \mathrm{CC} \\
(p \text { value })\end{array}$ & NS & NS & NS & NS \\
\hline & $\begin{array}{c}\text { CC versus HFDs } \\
(p \text { value }) \\
\end{array}$ & $0.048^{*}$ & $0.001^{*}$ & $0.017^{*}$ & $0.023^{*}$ \\
\hline Post-NAC GPR versus PPR & $\begin{array}{c}\text { GPR CC versus PPR CC } \\
(p \text { value })\end{array}$ & NS & $0.041^{*}$ & NS & NS \\
\hline
\end{tabular}

LLABCs: large and locally advanced breast cancers; NAC: neoadjuvant chemotherapy; GPRs: complete or $\geq 90 \%$ reduction of tumour cell mass; PPRs: no or $\leq 90 \%$ reduction of tumour cell mass; HFDs: healthy female donors; NS: nonsignificant; * statistically significant.

TABLE 16: Expression (\%) of costimulatory and LNH molecules on mDC1s in the blood of women with LLABCs undergoing NAC. Baseline (B) levels in LLABCs versus completion of chemotherapy (CC) levels in different responders.

\begin{tabular}{|c|c|c|c|c|c|c|}
\hline Study group comparisons & & CD40 & CD80 & CD83 & CD86 & CD197 \\
\hline \multirow{4}{*}{ Good pathological responders (GPR: $n=9$ ) } & $\mathrm{B}(\%)$ & $40.60 \pm 10.00$ & $2.02 \pm 1.30$ & $4.45 \pm 0.75$ & $40.97 \pm 14.00$ & $31.29 \pm 8.00$ \\
\hline & CC $(\%)$ & $43.13 \pm 10.00$ & $3.83 \pm 2.00$ & $3.71 \pm 1.70$ & $28.66 \pm 7.00$ & $48.34 \pm 14.00$ \\
\hline & $\begin{array}{c}\text { B versus CC } \\
(p \text { value })\end{array}$ & NS & NS & NS & NS & NS \\
\hline & $\begin{array}{c}\text { CC versus HFDs } \\
(p \text { value })\end{array}$ & NS & NS & NS & NS & NS \\
\hline \multirow{4}{*}{ Poor pathological responders (PPRs: $n=7$ ) } & $\mathrm{B}(\%)$ & $26.80 \pm 10.00$ & $1.48 \pm 0.50$ & $2.98 \pm 2.00$ & $21.37 \pm 10.00$ & $22.73 \pm 6.00$ \\
\hline & $\mathrm{CC}(\%)$ & $16.80 \pm 8.00$ & $2.29 \pm 1.20$ & $4.47 \pm 1.80$ & $6.81 \pm 6.00$ & $13.83 \pm 5.00$ \\
\hline & $\begin{array}{c}\text { B versus CC } \\
\quad(p \text { value })\end{array}$ & NS & NS & NS & NS & NS \\
\hline & $\begin{array}{c}\text { CC versus HFDs } \\
\text { ( } p \text { value })\end{array}$ & $0.001^{*}$ & NS & NS & $0.001^{*}$ & NS \\
\hline Post-NAC GPR versus PPR & $\begin{array}{c}\text { GPR CC versus PPR CC } \\
(p \text { value })\end{array}$ & $0.005^{*}$ & NS & NS & $0.004^{*}$ & $0.003^{*}$ \\
\hline
\end{tabular}

LNH: lymph node homing; LLABCs: large and locally advanced breast cancers; NAC: neoadjuvant chemotherapy; GPRs: complete or $>90 \%$ reduction of tumour cell mass; PPRs: no or $\leq 90 \%$ reduction of tumour cell mass; HFDs: healthy female donors; NS: nonsignificant; *statistically significant.

Our study has provided further knowledge and understanding of the relevance and contribution of certain components of innate immunity to tumour cell death in both the primary breast cancer and metastases in tumour-draining ALNs in women with LLABCs undergoing NAC. High levels of TIMs (M2) appear to induce/enhance pCRs in primary and ALN metastatic breast cancers probably through their association with high tumour grade and negative ER status. High level of expression of VEGF and the resultant increased vascularity results in enhanced delivery of chemotherapeutic agents to the tumour cell milieu. Circulating levels of DCs and expression of HLA-DR and costimulatory molecules were significantly reduced in patients with LLABCs. This diminished number of activated DCs and thus decreased capacity to present TAAs (released by NAC and innate NK cells) to naïve adaptive $\mathrm{T}$ cells results in reduced generation of CTLs. This trend was significantly reversed in patients in whom NAC induced a pCR. These various immune mechanisms highlight the close and important interaction between innate and adaptive anticancer immunity.

\section{Conclusion}

There is a significant body of evidence documenting the important contribution by circulating and tumourinfiltrating $\mathrm{T}$ effector $\left(\mathrm{CD} 4^{+}\right.$and $\mathrm{CD} 8^{+}$) and regulatory $\left(\mathrm{FOXP}^{+}{ }^{+}\right.$and CTLA $\left.-4^{+}\right)$cells and NK cells in immunemediated breast cancer cell death in women with LLABCs 
undergoing NAC. Our novel findings have further increased our knowledge and documented the important contribution of innate immunity to tumour cell death in women with LLABCs undergoing NAC. The significant associations between the beneficial pathological responses (GPR and $\mathrm{pCR}$ ) in the tumour microenvironment (primary and ALN metastases) and key innate immune cells (CD163 ${ }^{+}$TIMs, circulating PMN neutrophils, and DCs/subsets) complement our findings with NK cells and are an important contribution to the understanding of putative anticancer immune responses in NAC, resulting in immune-mediated tumour cell death.

\section{Abbreviations}

\begin{tabular}{|c|c|}
\hline A: & Adriamycin \\
\hline ALN: & Axillary lymph node \\
\hline C: & Cyclophosphamide \\
\hline CD: & Cluster of differentiation \\
\hline CTL: & Cytotoxic T lymphocyte \\
\hline DAB: & Diaminobenzidine \\
\hline DFS: & Disease-free survival \\
\hline DC: & Dendritic cell \\
\hline ER: & Oestrogen receptor \\
\hline FOXP3: & Forkhead box protein 3 \\
\hline GPR: & Good pathological response \\
\hline HPF: & High-power field \\
\hline HRP: & Horseradish peroxidase \\
\hline IDO: & Indoleamine 2,3-dioxygenase \\
\hline IHC: & Immunohistochemistry \\
\hline IL: & Interleukin \\
\hline IFN- $\gamma:$ & Interferon-gamma \\
\hline LLABC: & Large and locally advanced breast cancer \\
\hline MAb: & Monoclonal antibody \\
\hline mDC: & Myeloid-derived dendritic cell \\
\hline NAC: & Neoadjuvant chemotherapy \\
\hline NK: & Natural killer \\
\hline OS: & Overall survival \\
\hline pCR: & Pathological complete response \\
\hline pDC: & Plasmacytoid dendritic cell \\
\hline PMN: & Polymorphonuclear neutrophil \\
\hline PPR: & Poor pathological response \\
\hline RT: & Room temperature \\
\hline SLN: & Sentinel lymph node \\
\hline SOCS: & Suppression of cytokine signalling \\
\hline $\mathrm{T}:$ & Docetaxel \\
\hline TAA: & Tumour-associated antigen \\
\hline Th: & T helper \\
\hline TIN: & Tumour-infiltrating neutrophil \\
\hline TIM: & Tumour-infiltrating macrophage \\
\hline Treg: & $\mathrm{T}$ regulatory cell \\
\hline TGF- $\beta$ : & Transforming growth factor-beta \\
\hline TIL: & Tumour-infiltrating lymphocyte \\
\hline VEGF: & Vascular endothelial growth factor \\
\hline $\mathrm{X}:$ & Capecitabine. \\
\hline
\end{tabular}

\section{Conflicts of Interest}

The authors declare that they have no competing interests.

\section{Authors' Contributions}

Viriya Kaewkangsadan, Chandan Verma, Jennifer M. Eremin, Gerard Cowley, and Oleg Eremin conceptualised and designed the manuscript. Viriya Kaewkangsadan, Chandan Verma, Jennifer M. Eremin, Gerard Cowley, and Oleg Eremin are assigned in the data acquisition. Viriya Kaewkangsadan, Chandan Verma, Jennifer $M$. Eremin, Gerard Cowley, Mohammad Ilyas, and Oleg Eremin analysed and interpreted the data. Viriya Kaewkangsadan, Chandan Verma, and Gerard Cowley performed the laboratory assays. Viriya Kaewkangsadan, Chandan Verma, Jennifer M. Eremin, and Oleg Eremin wrote the manuscript. Viriya Kaewkangsadan, Chandan Verma, Jennifer M. Eremin, Gerard Cowley, Mohammad Ilyas, Sukchai Satthaporn, and Oleg Eremin reviewed and approved the final version of the manuscript.

\section{Acknowledgments}

The authors wish to acknowledge Mr. Christopher Nolan (Academic Unit of Clinical Oncology, City Hospital, University of Nottingham) for his advice and help with the IHC assays. The clinical trial, from which patients' tissue specimens and blood samples were collected for the study, was supported by educational grants from Sanofi-Aventis UK, Roche UK, and Chugai UK. The authors wish to acknowledge the financial support provided for this study by a grant from the Nottinghamshire, Derbyshire and Lincolnshire Research Alliance and Candles Charity.

\section{References}

[1] M. Aloysius, L. Walker, and O. Eremin, "Cancer and the immune response Ch 4," in Essential Immunology for Surgeons, O. Eremin and H. Sewell, Eds., OUP, Oxford, 2011.

[2] W. H. Fridman, J. Galon, F. Pages, E. Tartour, C. SautesFridman, and G. Kroemer, "Prognostic and predictive impact of intra- and peritumoral immune infiltrates," Cancer Research, vol. 71, no. 17, pp. 5601-5605, 2011.

[3] J. Galon, H. K. Angell, D. Bedognetti, and F. M. Marincola, "The continuum of cancer immunosurveillance: prognostic, predictive, and mechanistic signatures," Immunity, vol. 39, no. 1, pp. 11-26, 2013.

[4] M. W. Teng, S. F. Ngiow, A. Ribas, and M. J. Smyth, "Classifying cancers based on T-cell infiltration and PD-L1," Cancer Research, vol. 75, no. 11, pp. 2139-2145, 2015.

[5] L. Zhang, J. R. Conejo-Garcia, D. Katsaros et al., "Intratumoral T cells, recurrence, and survival in epithelial ovarian cancer," The New England Journal of Medicine, vol. 348, no. 3, pp. 203-213, 2003.

[6] F. Pages, A. Berger, M. Camus et al., "Effector memory T cells, early metastasis, and survival in colorectal cancer," The New England Journal of Medicine, vol. 353, no. 25, pp. 2654-2666, 2005.

[7] W. H. Fridman, F. Pages, C. Sautes-Fridman, and J. Galon, "The immune contexture in human tumours: impact on clinical outcome," Nature Reviews Cancer, vol. 12, no. 4, pp. 298-306, 2012. 
[8] H. Angell and J. Galon, "From the immune contexture to the immunoscore: the role of prognostic and predictive immune markers in cancer," Current Opinion in Immunology, vol. 25, no. 2, pp. 261-267, 2013.

[9] C. Denkert, S. Loibl, A. Noske et al., "Tumor-associated lymphocytes as an independent predictor of response to neoadjuvant chemotherapy in breast cancer," Journal of Clinical Oncology: Official Journal of the American Society of Clinical Oncology, vol. 28, no. 1, pp. 105-113, 2010.

[10] R. Yamaguchi, M. Tanaka, A. Yano et al., "Tumor-infiltrating lymphocytes are important pathologic predictors for neoadjuvant chemotherapy in patients with breast cancer," Human Pathology, vol. 43, no. 10, pp. 1688-1694, 2012.

[11] M. Ono, H. Tsuda, C. Shimizu et al., "Tumor-infiltrating lymphocytes are correlated with response to neoadjuvant chemotherapy in triple-negative breast cancer," Breast Cancer Research and Treatment, vol. 132, no. 3, pp. 793-805, 2012.

[12] M. V. Dieci, C. Criscitiello, A. Goubar et al., "Prognostic value of tumor-infiltrating lymphocytes on residual disease after primary chemotherapy for triple-negative breast cancer: a retrospective multicenter study," Annals of Oncology: Official Journal of the European Society for Medical Oncology/ESMO, vol. 25, 2014.

[13] V. Kaewkangsadan, C. Verma, J. M. Eremin, G. Cowley, M. Ilyas, and O. Eremin, "Crucial contributions by T lymphocytes (effector, regulatory, and checkpoint inhibitor) and cytokines (TH1, TH2, and TH17) to a pathological complete response induced by neoadjuvant chemotherapy in women with breast cancer," Journal of Immunology Research, vol. 2016, Article ID 4757405, 25 pages, 2016.

[14] S. Ladoire, G. Mignot, S. Dabakuyo et al., "In situ immune response after neoadjuvant chemotherapy for breast cancer predicts survival," The Journal of Pathology, vol. 224, no. 3, pp. 389-400, 2011.

[15] F. Liu, Y. Li, M. Ren et al., "Peritumoral FOXP3(+) regulatory $\mathrm{T}$ cell is sensitive to chemotherapy while intratumoral FOXP3(+) regulatory $\mathrm{T}$ cell is prognostic predictor of breast cancer patients," Breast Cancer Research and Treatment, vol. 135, no. 2, pp. 459-467, 2012.

[16] A. N. Seo, H. J. Lee, E. J. Kim et al., “Tumour-infiltrating CD8+ lymphocytes as an independent predictive factor for pathological complete response to primary systemic therapy in breast cancer," British Journal of Cancer, vol. 109, no. 10, pp. 27052713, 2013.

[17] E. Garcia-Martinez, G. L. Gil, A. C. Benito et al., "Tumor-infiltrating immune cell profiles and their change after neoadjuvant chemotherapy predict response and prognosis of breast cancer," Breast Cancer Research, vol. 16, no. 6, p. 488, 2014.

[18] R. J. Steele, M. Brown, and O. Eremin, "Characterisation of macrophages infiltrating human mammary carcinomas," British Journal of Cancer, vol. 51, no. 1, pp. 135-138, 1985.

[19] J. W. Pollard, "Macrophages define the invasive microenvironment in breast cancer," Journal of Leukocyte Biology, vol. 84, no. 3, pp. 623-630, 2008.

[20] R. D. Leek, C. E. Lewis, R. Whitehouse, M. Greenall, J. Clarke, and A. L. Harris, "Association of macrophage infiltration with angiogenesis and prognosis in invasive breast carcinoma," Cancer Research, vol. 56, no. 20, pp. 4625-4629, 1996.

[21] V. Goede, L. Brogelli, M. Ziche, and H. G. Augustin, "Induction of inflammatory angiogenesis by monocyte chemoattractant protein-1," International Journal of Cancer Journal International du Cancer, vol. 82, no. 5, pp. 765-770, 1999.
[22] L. Bingle, N. J. Brown, and C. E. Lewis, "The role of tumourassociated macrophages in tumour progression: implications for new anticancer therapies," The Journal of Pathology, vol. 196, no. 3, pp. 254-265, 2002.

[23] S. Tsutsui, K. Yasuda, K. Suzuki, K. Tahara, H. Higashi, and S. Era, "Macrophage infiltration and its prognostic implications in breast cancer: the relationship with VEGF expression and microvessel density," Oncology Reports, vol. 14, no. 2, pp. 425-431, 2005.

[24] S. D. Heys, K. N. Stewart, E. J. McKenzie et al., "Characterisation of tumour-infiltrating macrophages: impact on response and survival in patients receiving primary chemotherapy for breast cancer," Breast Cancer Research and Treatment, vol. 135, no. 2, pp. 539-548, 2012.

[25] C. T. Pham, "Neutrophil serine proteases: specific regulators of inflammation," Nature Reviews Immunology, vol. 6, no. 7, pp. 541-550, 2006.

[26] C. A. Dumitru, K. Moses, S. Trellakis, S. Lang, and S. Brandau, "Neutrophils and granulocytic myeloid-derived suppressor cells: immunophenotyping, cell biology and clinical relevance in human oncology," Cancer Immunology, Immunotherapy, vol. 61, no. 8, pp. 1155-1167, 2012.

[27] E. Di Carlo, G. Forni, P. Lollini, M. P. Colombo, A. Modesti, and P. Musiani, "The intriguing role of polymorphonuclear neutrophils in antitumor reactions," Blood, vol. 97, no. 2, pp. 339-345, 2001.

[28] A. M. Houghton, "The paradox of tumor-associated neutrophils: fueling tumor growth with cytotoxic substances," Cell Cycle, vol. 9, no. 9, pp. 1732-1737, 2010.

[29] J. Jablonska, S. Leschner, K. Westphal, S. Lienenklaus, and S. Weiss, "Neutrophils responsive to endogenous IFN-beta regulate tumor angiogenesis and growth in a mouse tumor model," The Journal of Clinical Investigation, vol. 120, no. 4, pp. 1151-1164, 2010.

[30] A. Bellocq, M. Antoine, A. Flahault et al., "Neutrophil alveolitis in bronchioloalveolar carcinoma: induction by tumor-derived interleukin-8 and relation to clinical outcome," The American Journal of Pathology, vol. 152, no. 1, pp. 83-92, 1998.

[31] H. K. Jensen, F. Donskov, N. Marcussen, M. Nordsmark, F. Lundbeck, and H. von der Maase, "Presence of intratumoral neutrophils is an independent prognostic factor in localized renal cell carcinoma," Journal of Clinical Oncology: Official Journal of the American Society of Clinical Oncology, vol. 27, no. 28, pp. 4709-4717, 2009.

[32] Y. W. Li, S. J. Qiu, J. Fan et al., "Intratumoral neutrophils: a poor prognostic factor for hepatocellular carcinoma following resection," Journal of Hepatology, vol. 54, no. 3, pp. 497-505, 2011.

[33] M. Ilie, V. Hofman, C. Ortholan et al., "Predictive clinical outcome of the intratumoral CD66b-positive neutrophil-toCD8-positive T-cell ratio in patients with resectable nonsmall cell lung cancer," Cancer, vol. 118, no. 6, pp. 1726-1737, 2012.

[34] J. Idoyaga and R. M. Steinman, "SnapShot: dendritic cells," Cell, vol. 146, no. 4, p. 660.e2, 2011.

[35] T. S. Mathan, C. G. Figdor, and S. I. Buschow, "Human plasmacytoid dendritic cells: from molecules to intercellular communication network," Frontiers in Immunology, vol. 4, p. 372, 2013.

[36] J. Banchereau and R. M. Steinman, "Dendritic cells and the control of immunity," Nature, vol. 392, no. 6673, pp. 245 252, 1998. 
[37] K. Palucka and J. Banchereau, "SnapShot: cancer vaccines," Cell, vol. 157, no. 2, p. 516.e1, 2014.

[38] A. J. Tesone, N. Svoronos, M. J. Allegrezza, and J. R. ConejoGarcia, "Pathological mobilization and activities of dendritic cells in tumor-bearing hosts: challenges and opportunities for immunotherapy of cancer," Frontiers in Immunology, vol. 4, p. $435,2013$.

[39] S. Satthaporn and O. Eremin, "Dendritic cells (II): role and therapeutic implications in cancer," Journal of the Royal College of Surgeons of Edinburgh, vol. 46, no. 3, pp. 159-167, 2001.

[40] E. E. Hillenbrand, A. M. Neville, and B. J. Coventry, "Immunohistochemical localization of CD1a-positive putative dendritic cells in human breast tumours," British Journal of Cancer, vol. 79, no. 5-6, pp. 940-944, 1999.

[41] B. J. Coventry, P. L. Lee, D. Gibbs, and D. N. Hart, "Dendritic cell density and activation status in human breast cancer-CD1a, CMRF-44, CMRF-56 and CD-83 expression," British Journal of Cancer, vol. 86, no. 4, pp. 546-551, 2002.

[42] A. S. Mansfield, P. Heikkila, K. von Smitten, J. Vakkila, and M. Leidenius, "Metastasis to sentinel lymph nodes in breast cancer is associated with maturation arrest of dendritic cells and poor co-localization of dendritic cells and CD8+ T cells," Virchows Archiv: An International Journal of Pathology, vol. 459, no. 4, pp. 391-398, 2011.

[43] S. Satthaporn, A. Robins, W. Vassanasiri et al., "Dendritic cells are dysfunctional in patients with operable breast cancer," Cancer Immunology, Immunotherapy, vol. 53, no. 6, pp. 510518, 2004.

[44] B. J. Coventry and J. Morton, "CD1a-positive infiltratingdendritic cell density and 5-year survival from human breast cancer," British Journal of Cancer, vol. 89, no. 3, pp. 533-538, 2003.

[45] C. Verma, V. Kaewkangsadan, J. M. Eremin et al., "Natural killer (NK) cell profiles in blood and tumour in women with large and locally advanced breast cancer (LLABC) and their contribution to a pathological complete response (PCR) in the tumour following neoadjuvant chemotherapy (NAC): differential restoration of blood profiles by NAC and surgery," Journal of Translational Medicine, vol. 13, p. 180, 2015.

[46] J. Eremin, G. Cowley, L. G. Walker, E. Murray, M. Stovickova, and O. Eremin, "Women with large $(\geq 3 \mathrm{~cm})$ and locally advanced breast cancers (T3, 4, N1, 2, M0) receiving neoadjuvant chemotherapy (NAC: cyclophosphamide, doxorubicin, docetaxel): addition of capecitabine improves 4-year diseasefree survival," SpringerPlus, vol. 4, p. 9, 2015.

[47] K. N. Ogston, I. D. Miller, S. Payne et al., "A new histological grading system to assess response of breast cancers to primary chemotherapy: prognostic significance and survival," Breast, vol. 12, no. 5, pp. 320-327, 2003.

[48] L. G. Walker, J.M. Eremin, M. M. Aloysius et al., "Effects on quality of life, anti-cancer responses, breast conserving surgery and survival with neoadjuvant docetaxel: a randomised study of sequential weekly versus three-weekly docetaxel following neoadjuvant doxorubicin and cyclophosphamide in women with primary breast cancer," BMC Cancer, vol. 11, p. 179, 2011.

[49] J. Forssell, A. Oberg, M. L. Henriksson, R. Stenling, A. Jung, and R. Palmqvist, "High macrophage infiltration along the tumor front correlates with improved survival in colon cancer," Clinical Cancer Research: An Official Journal of the American Association for Cancer Research, vol. 13, no. 5, pp. 1472-1479, 2007.
[50] Q. Zhou, R. Q. Peng, X. J. Wu et al., "The density of macrophages in the invasive front is inversely correlated to liver metastasis in colon cancer," Journal of Translational Medicine, vol. 8, p. 13, 2010.

[51] S. Edin, M. L. Wikberg, A. M. Dahlin et al., "The distribution of macrophages with a M1 or M2 phenotype in relation to prognosis and the molecular characteristics of colorectal cancer," PLoS One, vol. 7, no. 10, article e47045, 2012.

[52] N. Oda, K. Shimazu, Y. Naoi et al., "Intratumoral regulatory T cells as an independent predictive factor for pathological complete response to neoadjuvant paclitaxel followed by 5 FU/epirubicin/cyclophosphamide in breast cancer patients," Breast Cancer Research and Treatment, vol. 136, no. 1, pp. 107-116, 2012.

[53] L. Demir, S. Yigit, H. Ellidokuz et al., "Predictive and prognostic factors in locally advanced breast cancer: effect of intratumoral FOXP3+ Tregs," Clinical \& Experimental Metastasis, vol. 30, 2013.

[54] A. S. Mansfield, P. Heikkila, K. von Smitten, J. Vakkila, and M. Leidenius, "The presence of sinusoidal CD163(+) macrophages in lymph nodes is associated with favorable nodal status in patients with breast cancer," Virchows Archiv: An International Journal of Pathology, vol. 461, no. 6, pp. 639-646, 2012.

[55] K. S. McCarty Jr., L. S. Miller, E. B. Cox, J. Konrath, and K. S. McCarty Sr., "Estrogen receptor analyses. Correlation of biochemical and immunohistochemical methods using monoclonal antireceptor antibodies," Archives of Pathology \& Laboratory Medicine, vol. 109, no. 8, pp. 716-721, 1985.

[56] L. C. Collins, M. L. Botero, and S. J. Schnitt, "Bimodal frequency distribution of estrogen receptor immunohistochemical staining results in breast cancer: an analysis of 825 cases," American Journal of Clinical Pathology, vol. 123, no. 1, pp. 16-20, 2005.

[57] C. Verma, J. M. Eremin, A. Robins et al., "Abnormal T regulatory cells (Tregs: FOXP3+, CTLA-4+), myeloid-derived suppressor cells (MDSCs: monocytic, granulocytic) and polarised $\mathrm{T}$ helper cell profiles (Th1, Th2, Th17) in women with large and locally advanced breast cancers undergoing neoadjuvant chemotherapy (NAC) and surgery: failure of abolition of abnormal treg profile with treatment and correlation of treg levels with pathological response to NAC," Journal of Translational Medicine, vol. 11, p. 16, 2013.

[58] W. Sha, B. Brune, and A. Weigert, "The multi-faceted roles of prostaglandin E2 in cancer-infiltrating mononuclear phagocyte biology," Immunobiology, vol. 217, no. 12, pp. 1225$1232,2012$.

[59] C. Murdoch, M. Muthana, S. B. Coffelt, and C. E. Lewis, "The role of myeloid cells in the promotion of tumour angiogenesis," Nature Reviews Cancer, vol. 8, no. 8, pp. 618-631, 2008.

[60] A. Mantovani, P. Allavena, A. Sica, and F. Balkwill, "Cancerrelated inflammation," Nature, vol. 454, no. 7203, pp. 436444, 2008.

[61] S. K. Moestrup and H. J. Moller, "CD163: a regulated hemoglobin scavenger receptor with a role in the anti-inflammatory response," Annals of Medicine, vol. 36, no. 5, pp. 347-354, 2004.

[62] B. Z. Qian and J. W. Pollard, "Macrophage diversity enhances tumor progression and metastasis," Cell, vol. 141, no. 1, pp. 39-51, 2010.

[63] C. Porta, B. Subhra Kumar, P. Larghi, L. Rubino, A. Mancino, and A. Sica, "Tumor promotion by tumor-associated 
macrophages," Advances in Molecular Oncology, vol. 604, pp. 67-86, 2007.

[64] A. Boissonnas, F. Licata, L. Poupel et al., "CD8+ tumorinfiltrating $\mathrm{T}$ cells are trapped in the tumor-dendritic cell network," Neoplasia, vol. 15, no. 1, pp. 85-94, 2013.

[65] R. Noy and J. W. Pollard, "Tumor-associated macrophages: from mechanisms to therapy," Immunity, vol. 41, no. 1, pp. 49-61, 2014.

[66] G. von Minckwitz, M. Untch, J. U. Blohmer et al., "Definition and impact of pathologic complete response on prognosis after neoadjuvant chemotherapy in various intrinsic breast cancer subtypes," Journal of Clinical Oncology: Official Journal of the American Society of Clinical Oncology, vol. 30, no. 15, pp. 1796-1804, 2012.

[67] P. Cortazar, L. Zhang, M. Untch et al., "Pathological complete response and long-term clinical benefit in breast cancer: the CTNeoBC pooled analysis," Lancet, vol. 384, no. 9938, pp. 164-172, 2014.

[68] E. H. Lips, L. Mulder, J. J. de Ronde et al., "Breast cancer subtyping by immunohistochemistry and histological grade outperforms breast cancer intrinsic subtypes in predicting neoadjuvant chemotherapy response," Breast Cancer Research and Treatment, vol. 140, no. 1, pp. 63-71, 2013.

[69] L. J. Esserman, D. A. Berry, A. DeMichele et al., "Pathologic complete response predicts recurrence-free survival more effectively by cancer subset: results from the I-SPY 1 TRIALCALGB 150007/150012, ACRIN 6657," Journal of Clinical Oncology: Official Journal of the American Society of Clinical Oncology, vol. 30, no. 26, pp. 3242-3249, 2012.

[70] B. S. Rose, E. P. Winer, and H. J. Mamon, "Perils of the pathologic complete response," Journal of Clinical Oncology: Official Journal of the American Society of Clinical Oncology, vol. 34, 2016.

[71] T. J. Curiel, S. Wei, H. Dong et al., "Blockade of B7-H1 improves myeloid dendritic cell-mediated antitumor immunity," Nature Medicine, vol. 9, no. 5, pp. 562-567, 2003.

[72] I. Perrot, D. Blanchard, N. Freymond et al., "Dendritic cells infiltrating human non-small cell lung cancer are blocked at immature stage," Journal of Immunology, vol. 178, no. 5, pp. 2763-2769, 2007.

[73] S. Tsujitani, T. Furukawa, R. Tamada, T. Okamura, K. Yasumoto, and K. Sugimachi, "Langerhans cells and prognosis in patients with gastric carcinoma," Cancer, vol. 59, no. 3, pp. 501-505, 1987.

[74] K. Ambe, M. Mori, and M. Enjoji, "S-100 protein-positive dendritic cells in colorectal adenocarcinomas. Distribution and relation to the clinical prognosis," Cancer, vol. 63, no. 3, pp. 496-503, 1989.

[75] N. A. Zeid and H. K. Muller, "S100 positive dendritic cells in human lung tumors associated with cell differentiation and enhanced survival," Pathology, vol. 25, no. 4, pp. 338343, 1993.

[76] D. Avigan, "Dendritic cells: development, function and potential use for cancer immunotherapy," Blood Reviews, vol. 13, no. 1, pp. 51-64, 1999.

[77] I. E. Dumitriu, D. R. Dunbar, S. E. Howie, T. Sethi, and C. D. Gregory, "Human dendritic cells produce TGF-beta 1 under the influence of lung carcinoma cells and prime the differentiation of CD4+CD25+Foxp3+ regulatory T cells," Journal of Immunology, vol. 182, no. 5, pp. 2795-2807, 2009.
[78] A. D. Garg, D. V. Krysko, T. Verfaillie et al., "A novel pathway combining calreticulin exposure and ATP secretion in immunogenic cancer cell death," The EMBO Journal, vol. 31, no. 5, pp. 1062-1079, 2012.

[79] G. Kroemer, L. Galluzzi, O. Kepp, and L. Zitvogel, "Immunogenic cell death in cancer therapy," Annual Review of Immunology, vol. 31, pp. 51-72, 2013.

[80] N. Tsavaris, C. Kosmas, M. Vadiaka, P. Kanelopoulos, and D. Boulamatsis, "Immune changes in patients with advanced breast cancer undergoing chemotherapy with taxanes," British Journal of Cancer, vol. 87, no. 1, pp. 21-27, 2002.

[81] F. Ghiringhelli, C. Menard, P. E. Puig et al., "Metronomic cyclophosphamide regimen selectively depletes CD4+CD25+ regulatory $\mathrm{T}$ cells and restores $\mathrm{T}$ and $\mathrm{NK}$ effector functions in end stage cancer patients," Cancer Immunology, Immunotherapy, vol. 56, no. 5, pp. 641-648, 2007.

[82] J. Y. Park, M. J. Jang, Y. H. Chung et al., "Doxorubicin enhances $\mathrm{CD} 4(+)$ T-cell immune responses by inducing expression of CD40 ligand and 4-1BB," International Immunopharmacology, vol. 9, no. 13-14, pp. 1530-1539, 2009.

[83] C. M. Barbon, M. Yang, G. D. Wands et al., "Consecutive low doses of cyclophosphamide preferentially target Tregs and potentiate T cell responses induced by DNA PLG microparticle immunization," Cellular Immunology, vol. 262, no. 2, pp. 150-161, 2010.

[84] M. Aloysius, C. Verma, and O. Eremin, "Therapy and host defences Ch 7," in Essential Immunology for Surgeons, O. Eremin and H. Sewell, Eds., OUP, Oxford, 2011.

[85] L. Menger, E. Vacchelli, S. Adjemian et al., "Cardiac glycosides exert anticancer effects by inducing immunogenic cell death," Science Translational Medicine, vol. 4, no. 143, article 143ra99, 2012.

[86] N. Casares, M. O. Pequignot, A. Tesniere et al., "Caspasedependent immunogenicity of doxorubicin-induced tumor cell death," The Journal of Experimental Medicine, vol. 202, no. 12, pp. 1691-1701, 2005.

[87] S. R. Mattarollo, S. Loi, H. Duret, Y. Ma, L. Zitvogel, and M. J. Smyth, "Pivotal role of innate and adaptive immunity in anthracycline chemotherapy of established tumors," Cancer Research, vol. 71, no. 14, pp. 4809-4820, 2011.

[88] J. Vincent, G. Mignot, F. Chalmin et al., "5-fluorouracil selectively kills tumor-associated myeloid-derived suppressor cells resulting in enhanced T cell-dependent antitumor immunity," Cancer Research, vol. 70, no. 8, pp. 3052-3061, 2010.

[89] G. M. Weir, R. S. Liwski, and M. Mansour, "Immune modulation by chemotherapy or immunotherapy to enhance cancer vaccines," Cancer, vol. 3, no. 3, pp. 3114-3142, 2011.

[90] A. W. Tong, B. Seamour, J. M. Lawson et al., "Cellular immune profile of patients with advanced cancer before and after taxane treatment," American Journal of Clinical Oncology, vol. 23, no. 5, pp. 463-472, 2000. 


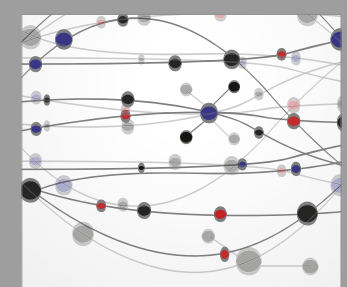

The Scientific World Journal
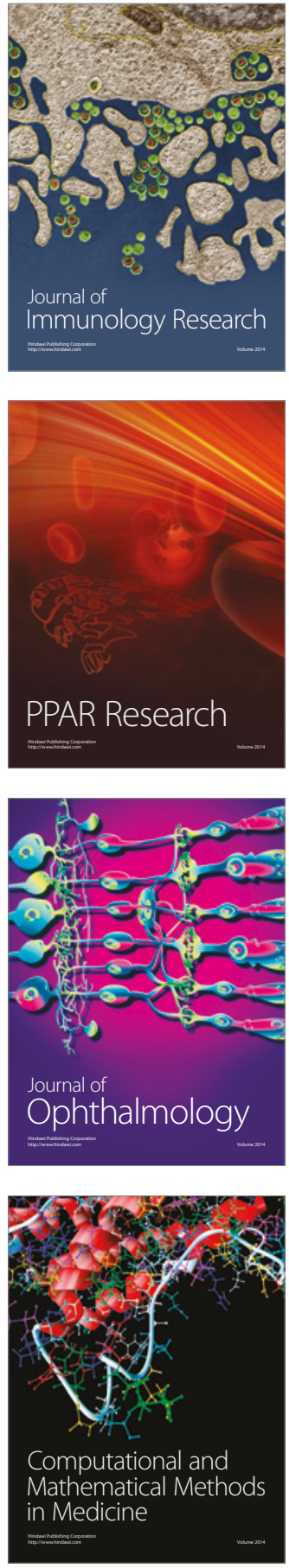

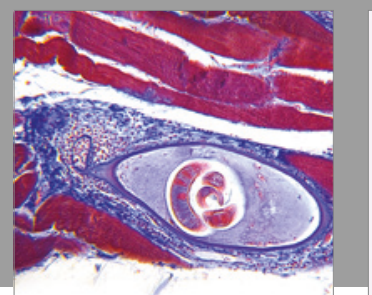

Gastroenterology Research and Practice
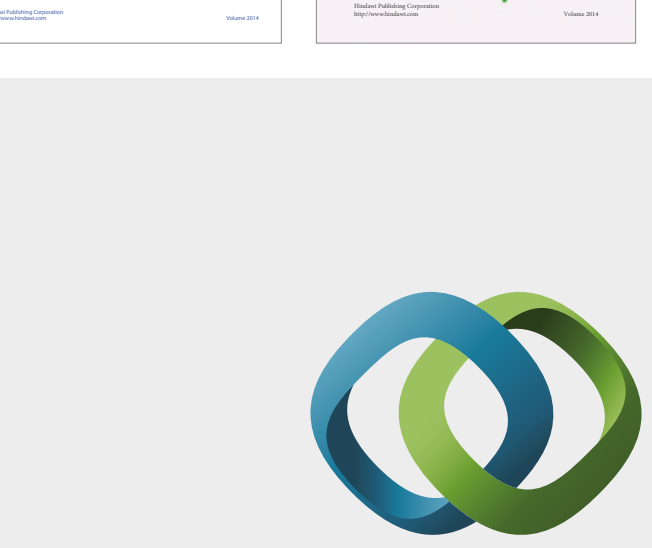

\section{Hindawi}

Submit your manuscripts at

https://www.hindawi.com
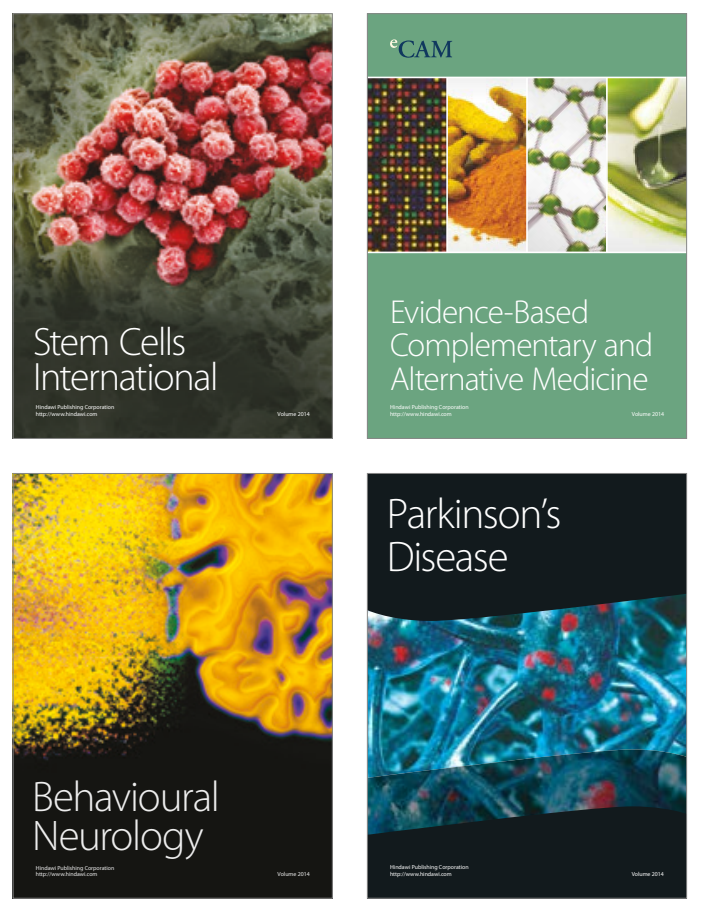
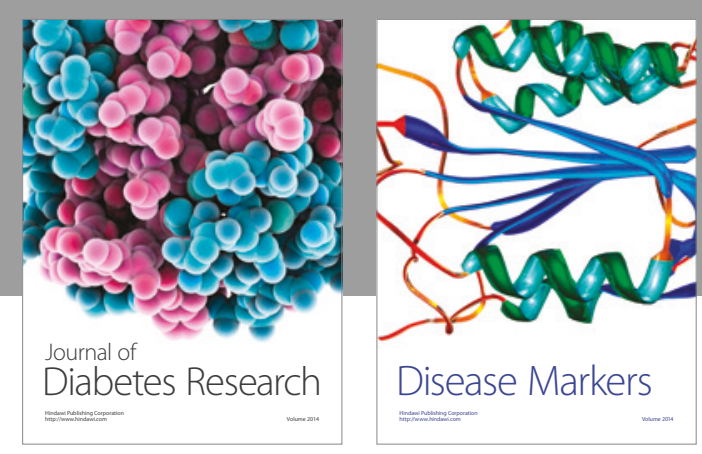

Disease Markers
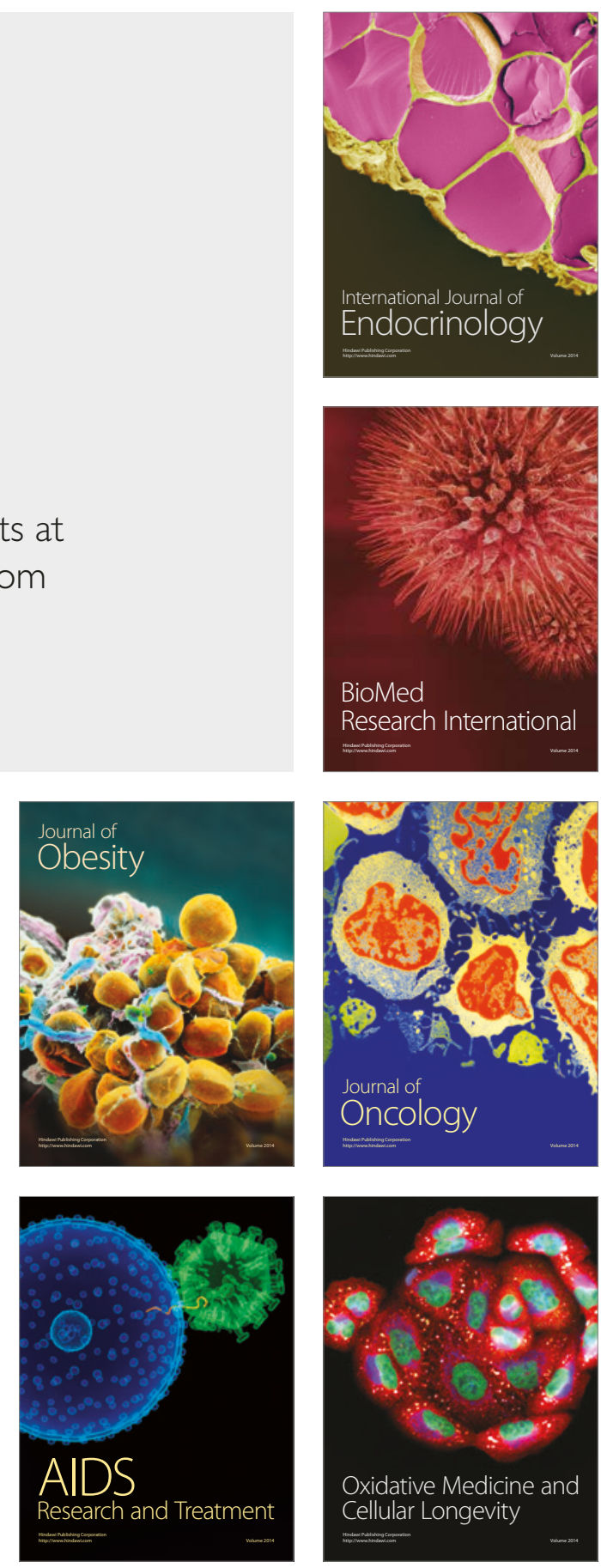